ISSN: 0514-7336

DOI: https://doi.org/10.14201/zephyrus201779173195

\title{
UN NUEVO OCULTAMIENTO MONETARIO DE BRONCES ROMANO-REPUBLICANOS Y DE CASTULO EN EL SUR DE HISPANIA: TORRE DE BENAGALBÓN (MÁLAGA)
}

\section{A new Republican Coin Hoard with Roman asses and coinage of Castulo bronzes from Southern Hispania: Torre de Benagalbón (Málaga)}

Bartolomé Mora Serrano* y Arturo Pérez Plaza**

* Dpto. de Ciencias Históricas (Área de Arqueología). Facultad de Filosofía y Letras-UMA. Campus de Teatinos. 29071 Málaga.Correo-e: barmora@uma.es

** Servicio de Protección del Patrimonio Histórico. Dirección General de Bienes Culturales y Museos. Consejería de Cultura de la Junta de Andalucía. C/ Levies, 27. 41004 Sevilla. Correo-e: arturo.perez@juntadeandalucia.es

Recepción: 16/12/2016; Revisión: 3/02/2017; Aceptación: 23/03/2017

Resumen: Durante la campaña de excavaciones arqueológicas de 2003-2004 en la villa romana de la Torre de Benagalbón (Rincón de la Victoria, Málaga), se localizó un modesto ocultamiento de moneda de bronce integrado por 19 ases y 1 semis romano-republicanos, junto con 9 unidades de la ceca ibérica meridional de Castulol Ka.ś.ti.l.o (Cazlona, Jaén). Este hallazgo contribuye al estudio de los ocultamientos mixtos -moneda romana y local- en el s de la Península Ibérica durante la segunda mitad del s. II a. C. Su singular composición plantea su formación en el distrito minero de Castulo, bien comunicado con el puerto de Malaca por una importante ruta documentada por las fuentes literarias y arqueológicas. Se discute también el prestigio de la moneda oficial romana sobre la local, especialmente después de 146/141 a. C., así como el perfil metrológico de estos ocultamientos y su transformación en el s. I a. C.

Palabras clave: Ocultamiento monetario; ases romano-republicanos; Castulo; Malaca; Hispania Ulterior.

Aвstract: During the excavations in the Roman villa of Torre de Benagalgón (Rincón de la Victoria, Málaga), in 2003-2004, a modest bronze coin hoard was discovered. It contained 19 Roman asses and one semis, and 9 units from Castulo/Ka.ś.ti.l.o (Cazlona, Jaén). This coin find contributes to the study of mixed bronze coin hoards -Roman and local coinage- in the south of Hispania during the second half of the second century BC. Its possible formation in the mining district of Castulo, well connected with de port of Malaca by an ancient pre-Roman road known by archaeological and literary sources, are discussed here. Finally, it is emphasized the role of Roman bronzes in relation to the local coinages, especially from 146/141 $\mathrm{BC}$, and also the changes in the metrological criteria during the 1 st century вс.

Key words: Coin Hoard; Roman Republican asses; Castulo; Malaca; Hispania Ulterior. 


\section{Presentación del hallazgo y su contexto arqueológico $^{1}$}

El yacimiento arqueológico de la Torre de Benagalbón, declarado Bien de Interés Cultural en 2008, es conocido por su importante villa marítima, asociada a un complejo termal de considerables dimensiones y, como suele ser habitual también en este tipo de asentamientos costeros, a una factoría de salazones (Rodríguez Oliva y Beltrán Fortes, 2008: 230232). Este importante complejo, cuya ocupación se extiende desde el s. II al v d. C., es la continuación de un asentamiento anterior que, a partir de materiales sin contexto arqueológico definido, se podría remontar a los ss. VII o vi a. C. (Recio y Perdiguero, 1986). También se documentan cerámicas romanas de época republicana, entre las que cabría destacar la campaniense A que apuntan, igualmente, a la ocupación de este estratégico enclave durante los ss. II-I a. C. (Serrano Ramos, 1985: 193). Fue en la campaña de 2003-2004 cuando en el sector norte del edificio termal se localizaron restos de construcciones hidráulicas: un canal de desagüe, posiblemente vinculado a varias piletas que, a su vez, se asocian a restos de muros mal definidos, sobre el que apareció el conjunto de monedas de bronce que justifica este estudio (Fig. 1).

Excavado parcialmente, por formar parte del perfil natural que conforma la suave ladera del pequeño cerro que da nombre al yacimiento, no es posible datar con precisión dichas estructuras -muros y restos de dos piletas-, aunque la presencia de algún material cerámico de época tardorrepublicana $\mathrm{y}$, sobre todo, los materiales que se asocian a las piletas y construcciones contiguas, de época altoimperial y con buenos paralelos en el yacimiento de la villa-factoría de Torrox-Costa (Rodríguez Oliva y Beltrán Fortes, 2008: 226-229), insisten en una ocupación del lugar en momentos anteriores al apogeo de la villa y termas. La cronología de las monedas que componen este ocultamiento, mediados del s. II a. C., es un dato a tener en cuenta, dada la

1 Este trabajo se enmarca en el proyecto de investigación del Ministerio de Economía y Competitividad de España (HAR2015-68669-P), así como en el Grupo de Investigación del PAIDI-HUM343. posición primaria de este ocultamiento; un pequeño escondrijo protegido por un fragmento cerámico de considerable tamaño, posiblemente un ánfora.

Todo parece indicar, a falta de datos más precisos, que este ocultamiento coincide con el abandono de unas instalaciones hidráulicas cuya cronología y función desconocemos. La posterior ocupación de este sector, integrado en las zonas aledańas al conjunto termal de la mencionada villa altoimperial, explicaría la alteración de este contexto tardorrepublicano con materiales cerámicos datables a partir de mediados del s. II d. C. En cuanto a la función de estas estructuras, descartando una conexión con el complejo termal romano ya aludido, no hay que descartar su posible uso industrial, bien relacionado con la fabricación de salazones y salsas de pescado, documentado en el entorno de la villa, pero en momentos posteriores, o bien con otro tipo de actividades como las metalúrgicas. En efecto, un aspecto destacado en la excavación de distintos sectores del yacimiento, también en el entorno de la pars urbana del mismo, incluidas las termas, es la destacada presencia de escorias de hierro, así como de calcopiritas; un mineral este último explotado desde época prehistórica en distintos puntos del Complejo Malágide, con numerosos afloramientos en los Montes del Málaga, así como en puntos cercanos al asentamiento de Benagalbón, asociados también a galena argentífera (Rodríguez Vinceiro et al., 1996: 195-196).

Sin que pueda ser evaluada en términos cuantitativos, ni siquiera cronológicos, parece claro que en este lugar se desarrolló una actividad metalúrgica. En este sentido, la aparición de un pequeño horno, de forma circular y semiexcavado en el suelo virgen, localizado bajo el pavimento de la factoría de salazones altoimperial, y asociado a escorias, así como a calcopirita en bruto, permite proponer una data más antigua para estas explotaciones.

En lo que concierne a las características del hallazgo monetario, junto a las monedas hay que destacar la presencia de un pequeño objeto metálico -diámetro: 41,03 mm y grosor: 0,95 mm-, de tendencia circular y que presenta dos pequeńos orificios situados cerca de sus extremos (Fig. 3, n. ${ }^{\circ} 30$ ). Debido a su deterioro, no podemos pronunciarnos 


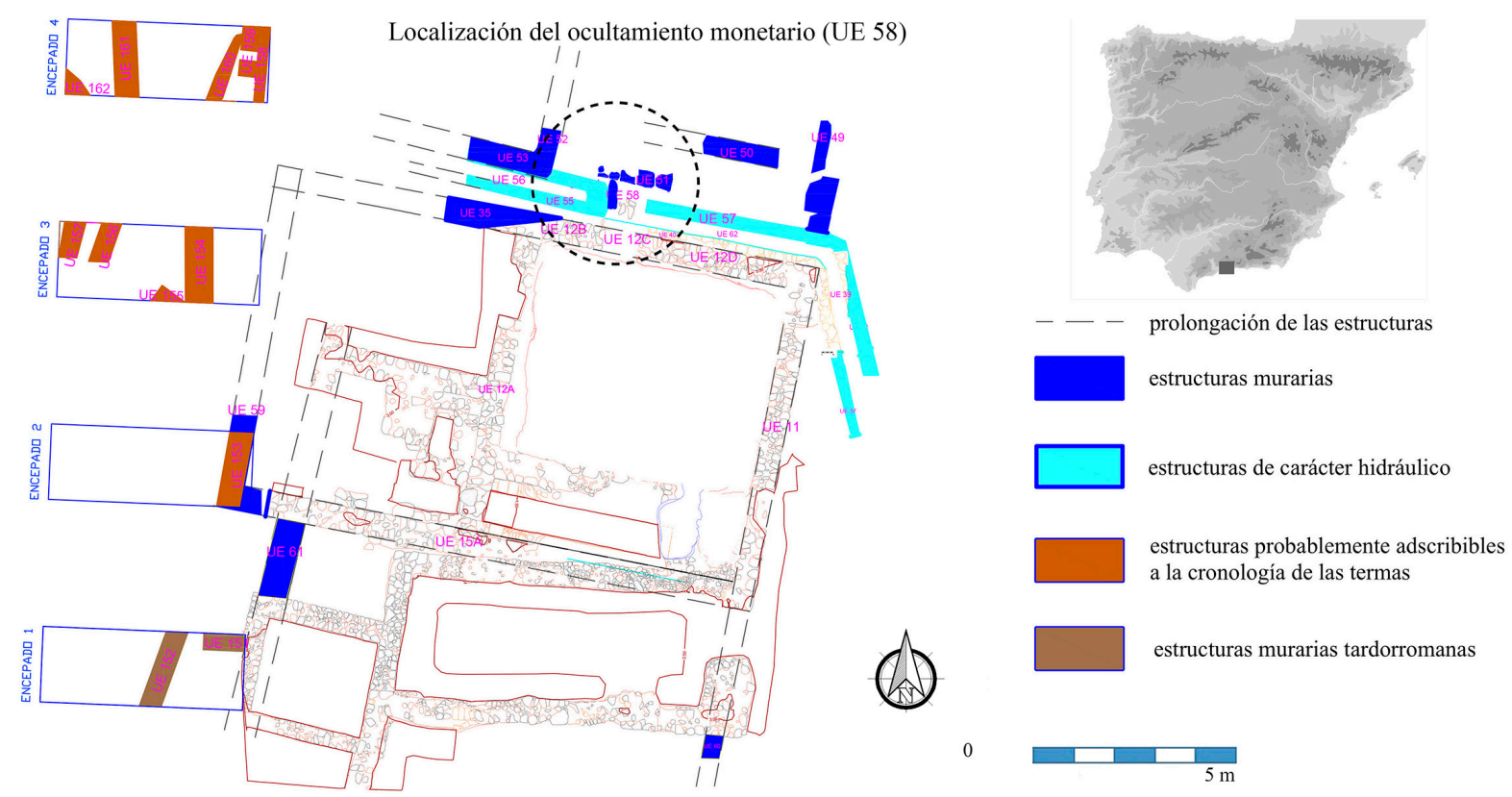

FIG. 1. Localización del ocultamiento monetario.

acerca de su función que bien pudiera tratarse de parte de una herramienta o utensilio doméstico, pero también de los restos de un platillo de balanza. Este tipo de objetos son de hallazgo relativamente frecuente en Hispania, tanto los asociados a la statera como, sobre todo, a la balanza simple o libra (Chaves Tristán y Pliego Vázquez, 2007: 240-242).

\section{Las monedas}

En toda introducción a la circulación monetaria antigua es habitual hacer hincapié en algunos conceptos clave como, para el caso que nos ocupa, sucede con los ocultamientos monetarios y los hallazgos aislados. Mientras que estos últimos se suelen considerar reflejo de la circulación monetaria en un yacimiento o zona geográfica, los ocultamientos presentan no pocos problemas de interpretación y no es tarea fácil responder a las muchas preguntas que suscitan este tipo de hallazgos.

Estas observaciones son especialmente tenidas en cuenta en el estudio de tesorillos con moneda de oro o plata (Campo, 1982: 63-64), pero no son ajenas a la interpretación de ocultamientos de moneda de bronce, como pone de manifiesto el hallazgo que nos ocupa. Ciertamente, incluso en ocultamientos con un número muy reducido de monedas, y con independencia del valor intrínseco de un conjunto numismático, siempre valioso en términos relativos para su poseedor, también tienen cabida típicos interrogantes como el criterio de selección o las posibles causas de su ocultamiento y posterior abandono, entre otras.

El hallazgo que nos ocupa tiene la virtud de ampliar en número y, sobre todo, en variedad el todavía muy escaso panorama de ocultamientos de moneda de bronce en Hispania entre el s. II e inicios del i a. C., y muy especialmente en la Ulterior-Baetica. Un territorio en el que el conocido tópico de su riqueza en hallazgos monetarios, incluidos los tesorillos, no se corresponde con la escasez de ocultamientos de moneda de bronce de época republicana, ya se trate de hallazgos bien documentados o de noticias poco precisas. Este vacío de información resulta todavía más patente en los ocultamientos que incluyen moneda de bronce oficial romana e hispana.

Así, después de casi 25 años, los ocultamientos de composición mixta de El Saucejo (Villaronga, 1980) y Écija (Chaves y García-Bellido, 1980) siguen siendo 
ASES ROMANO-REPUBLICANOS, ANÓNIMOS O INCLASIFICABLES. POST 2I I A. C.

\begin{tabular}{|c|c|}
\hline & $\begin{array}{l}\text { Anv. Cabeza laureada de Jano, encima barra } \\
\text { Rev. Proa, delante barra, debajo ROMA }\end{array}$ \\
\hline 1 & 45,2 g; 34,2 mm; 12 h.; Gastada. Mм P-10000.221 \\
\hline 2 & $\begin{array}{l}\text { 41,76 g; } 36,2 \mathrm{~mm} ; 12 \text {; Bastante Gastada (marca de punzón circular en } \\
\text { anverso); MM P-10000.222 }\end{array}$ \\
\hline 3 & 33,08 g; 33,9 mm; 6 h; Gastada; мм P-10000.223 \\
\hline 4 & 33,05 g; 32,7 mm; 12 h; Bastante Gastada; Mм P-10000.224 \\
\hline 5 & 26,38 g; 31,9 mm; 11 h; Bastante Gastada; MM P-10000.225 \\
\hline & Ases romano-republicanos con magistrado y/o símbolo \\
\hline 6 & $\begin{array}{l}\text { As } R R C 142 / 1 \text { c. } 189-180 \text { a. C. (Toro y } \underline{\mathrm{MD}} \text { ) } \\
25,49 \mathrm{~g} ; 33,1 \mathrm{~mm} ; 8 \mathrm{~h} \text {; Gastada. MM P-10000.226 } \\
\end{array}$ \\
\hline 7 & $\begin{array}{l}\text { As RRC 149/1a? c. } 189-180 \text { a. C. (L-MAMILI, Roma delante de proa) } \\
\text { 24,12; 31,1 mm; } 9 \text { h; Gastada. MM P-10000.227 }\end{array}$ \\
\hline 8 & $\begin{array}{l}\text { As } R R C \text { 173/1 c. } 169-158 \text { a. C. (C.SAX) } \\
33,11 \mathrm{~g} ; 33,1 \mathrm{~mm} ; 9 \text { h; Poco Gastada. MM P- } 10000.228\end{array}$ \\
\hline 9 & $\begin{array}{l}\text { As } R R C \text { 174/1 c. } 169-158 \text { a. C. (A.CAE) } \\
31,78 \mathrm{~g} ; 36,8 \mathrm{~mm} ; 4 \text { h; Gastada. MM P-10000.229 } \\
\end{array}$ \\
\hline 10 & $\begin{array}{l}\text { As RRC } 185 / 1 \text { c. } 169-158 \text { a. C. ( } \text { (VARo) } \\
30,12 \text { g; } 34 \text { mm; } 5 \text { h; Poco Gastada; MM P- } 10000.230\end{array}$ \\
\hline \begin{tabular}{|l|}
11 \\
\end{tabular} & $\begin{array}{l}\text { As RRC } 191 / 1 \text { c. } 169-158 \text { a. C. (vAL) } \\
16,46 \mathrm{~g} ; 30 \mathrm{~mm} ; 12 \mathrm{~h} \text {; Gastada; MM P-10000.231 } \\
\end{array}$ \\
\hline 12 & $\begin{array}{l}\text { As McCabe G. K1[As] c. 180-160 a. C. }{ }^{2} \\
28,34 \text { g; } 32,1 \mathrm{~mm} ; 5 \text { h; Gastada; mм P-10000.232 }\end{array}$ \\
\hline 13 & 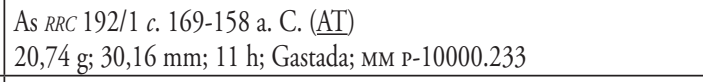 \\
\hline 14 & $\begin{array}{l}\text { As RRC 200/2 c. } 155 \text { a. C. (NAT) } \\
27,34 \text { g; } 35,1 \mathrm{~mm} ; 3 \text { h; Gastada; MM P- } 10000.234\end{array}$ \\
\hline 15 & $\begin{array}{l}\text { As } R R C \text { 203/2 c. } 153 \text { a. C. (C. } \underline{\text { MAIANI }} \text { ) } \\
23,75 \mathrm{~g} ; 34,5 \mathrm{~mm} \text {; } 11 \text { h.; Gastada; MM P- } 10000.235\end{array}$ \\
\hline 16 & $\begin{array}{l}\text { As RRC } 206 / 2 \text { c. } 150 \text { a. C. (SAFRA, delfín delante de proa) } \\
28,61 \text { g; } 30,04 \mathrm{~mm} \text {; 2; Poco Gastada; MM p-10000.236 }\end{array}$ \\
\hline 17 & $\begin{array}{l}\text { As RRC } 206 / 2 \text { c. } 150 \text { a. C. (SAFrA, delfín delante de proa) } \\
20,30 \mathrm{~g} ; 30,8 \mathrm{~mm} ; 5 \text { h; Poco Gastada; MM P- } 10000.237 \\
\end{array}$ \\
\hline 18 & $\begin{array}{l}\text { As RRC 215/2a c. } 148 \text { a. C. (c. MARC /LIBo, delante de proa) } \\
\text { 23,41 g; } 33 \mathrm{~mm} ; 11 \text { h; Gastada; MM P-10000.238 }\end{array}$ \\
\hline 19 & $\begin{array}{l}\text { As RRC 216/2a c. } 148 \text { a. C. (PITIo / L.SEMP) } \\
\text { 22,41 g; } 31 \mathrm{~mm} ; 11 \text { h; Poco Gastada; MM P-10000.239 }\end{array}$ \\
\hline & $\begin{array}{l}\text { Anv. Cabeza laureada de Saturno, delante S. } \\
\text { Rev. Proa, delante S, debajo ROMA }\end{array}$ \\
\hline 20 & $\begin{array}{l}\text { Semis } R R C \text { 188/2 o RRC 197-198в -c. 169-158 a. C. }{ }^{3} \\
17,76 \text { g; 26,6; 1; Poco Gastada; мM p-10000.240 } \\
\end{array}$ \\
\hline
\end{tabular}

FIG. 2. Inventario de las monedas romano-republicanas del hallazgo de la Torre de Benagalbón (Málaga).

el principal referente para valorar este tipo de hallazgos numismáticos en el sur peninsular; a los que cabe añadir el que aquí presentamos procedente de la Torre de Benagalbón (Rincón de la Victoria, Málaga). Los 20 bronces romanos -19 ases y 1 semis-, junto con las 9 unidades de Castulo, hacen de este ocultamiento el más numeroso de los de tipo mixto localizados en la Ulterior y, por tanto, permite profundizar en los criterios de selección y valoración de la moneda romana e indígena durante la segunda mitad del s. II a. C.

$\mathrm{Su}$ inventario, abreviado, queda como sigue (Figs. 2-3) ${ }^{4}$ :

\begin{tabular}{|c|c|}
\hline & Casth \\
\hline & $\begin{array}{l}\text { nv. Cabeza diademada a derecha con infulas colgando; gráflla de puntos. } \\
\text { Rev. Esfinge marchando a derecha; delante estrella; debajo inscripción } \\
\text { en ibérico meridional ka.ś.ti.l.o. }\end{array}$ \\
\hline 21 & $\begin{array}{l}\text { Unidad. Serie III o Iv (sin símbolo en anverso/reverso frustro) c. 195- } \\
\text { 179/165 a. C. CNH p. 332, n. }{ }^{0} \text { 9; p. 333, n. }{ }^{\circ} 23 \\
\text { 28,86 g; } 30,5 \text { mm; } 9 \text { h; Bastante Gastada; MM P-10000.241 }\end{array}$ \\
\hline 22 & $\begin{array}{l}\text { Unidad. Serie IVA (sin símbolo) c. } 179-165 \text { a. C. CNH p. } 333 \text { n. }^{\circ} 23 \\
23,36 \mathrm{~g} ; 32,9 \mathrm{~mm} ; 10 \text { h; Gastada; MM P-10000.242 }\end{array}$ \\
\hline 23 & 5 mm; 10 h; Gastada; мм P - 10000.243 \\
\hline 24 & 2 mm; 11 h; Algo Gastada; MM P-10000.244 \\
\hline 25 & $\begin{array}{l}\text { Unidad. Serie IvB }{ }^{5} \text { (símbolo de } \\
\text { 21,62 g; } 32,1 \mathrm{~mm} ; 12 \mathrm{~h} \text {; Gasta }\end{array}$ \\
\hline 26 & $\begin{array}{l}\text { Unidad. Serie va (símbolo mano) c. } 165-80 \text { a. C. } C N H \text { p. } 335, \text { n. }^{\circ} 38 \\
27,10 \text { g; } 31,2 \mathrm{~mm} ; 3 \text { h; Algo Gastada; MM P-10000.246 }\end{array}$ \\
\hline 27 & 25,49 g; 32,80 mm; 3 h; Algo Gastada; мM P- 10000.247 \\
\hline 28 & $21,63 \mathrm{~g} ; 29,9 \mathrm{~mm} ; 1$ h; Algo Gastada; Mм P-10000.248 \\
\hline 29 & $\begin{array}{l}\text { Unidad. Serie vB, } 4 \text { (símbolo creciente) c. 150-80 a. C.; CNH p. 335, } \\
\text { n. }{ }^{\circ} 32 \\
\text { 20,14 g; 29,9 mm; } 9 \text { h; Poco gastada; MM P-10000.249 }\end{array}$ \\
\hline
\end{tabular}

FIG. 3. Inventario de las monedas hispanas del hallazgo de la Torre de Benagalbón (Málaga); la numeración continúa la de la Fig. 2.

2 A pesar del mal estado de conservación de la moneda, la marca de valor de grueso trazado sobre la proa, de abultado remate, así parece indicarlo. Esta emisión está cercana a las RRC $183 / 1$ y 184/1a. C. El peso de nuestro ejemplar es algo elevado $-28,34 \mathrm{~g}-$ respecto a la media propuesta para esta serie de c. $25 \mathrm{~g}$, pero tampoco sobrepasa los pesos máximos de la muestra analizada. No se descarta la posibilidad, aunque nos parece menos probable, que se trate de una de las emisiones anónimas $R R C$ 197-198B/1b, bien documentada en Torelló, $c f$. Arévalo y Marcos, 1998: 24.

${ }^{3}$ La marca de valor delante de la proa podría encajar en el grupo k3 de McCabe (2013: 204), y por tanto podría tratarse de un divisor de la emisión $R R C$ 197-198в/1b. No obstante, el desgaste que presenta esta moneda, especialmente en el reverso, el ligero desplazamiento del cuño y, especialmente, su particular estilo aconsejan su inclusión en un grupo cercano: $R R C 188 / 2$ c. 169-158 a. C. Debemos esta apreciación a la amabilidad de A. McCabe (Londres).

4 Los números de las Figs. 2 y 3 se corresponden con los del inventario de las monedas, reproducidas a su tamaño natural. Las abreviaturas utilizadas en el catálogo y texto son 


\section{El ocultamiento monetario de Benagalbón en el contexto hispano}

Si analizamos las características de los ocultamientos de moneda de bronce surhispanos datables entre mediados del s. II y principios de la centuria siguiente, tomando como base $R R C H$ y ańadidos posteriores ${ }^{6}$, es evidente que el as romano-republicano es el nominal más apreciado y, posiblemente, sobrevalorado con respecto a la moneda local equiparable en peso y módulo. Ello justifica también la presencia, a veces mayoritaria o cuando menos abultada, de ejemplares muy gastados por su prolongado uso ya en el momento de su retirada de circulación; es decir, relacionables con la creciente escasez de este tipo de numerario provocada por la intermitente primero y drástica reducción más tarde de la emisión de ases a partir del 146 a. C., y su posterior cese en época de Sila (Crawford, 1985: 183-185; Bransbroug, 2011: 110-116).

Tal criterio selectivo se aprecia también en los ocultamientos formados exclusivamente por ases romano-republicanos, como el recientemente dado a conocer procedente del yacimiento de Castillejos II (Fuente de Cantos, Badajoz) (Conejo, 2014) compuesto por siete ases, de los que solo tres han podido ser identificados. Posiblemente encajaría también en este modelo el ocultamiento monetario de 25 ases romano-republicanos de Pinos Puente, la antigua Ilurco (Cerro de los Infantes, Granada), del que apenas conocemos otros datos que su metrología de c. 30 g (Chaves, 1991-1993: 268; Ruiz López, 2010: 1189).

Este modelo tiene, lógicamente, sus matices y excepciones, como por ejemplo se desprende del análisis de algunos ocultamientos de moneda de bronce procedentes de la futura Tarraconense datados entre el s. II a. C. e inicios del I a. C., que

las siguientes: $C N H=$ Villaronga, 1994; $R R C$ Crawford, 1974; $R R C H=$ Crawford, 1969; MM = Museo de Málaga.

5 Seguimos la ordenación propuesta por García-Bellido y Blázquez (2001: 229-231), donde la emisión con delfín es reasignada a la IVB, mientras que la siguiente serie paralela se corresponde ahora con la va -mano- y vb -creciente-.

6 Cf. Blázquez Cerrato, 1988; Villaronga, 1993b; García-Bellido y Blázquez, 2001; Ruiz López, 2010. combinan ases romano-republicanos y moneda local. Allí encontramos casos en los que coinciden numerario de peso y módulo reducidos, como sucede en uno de los recuperados en Ampurias en el que una de las dos monedas romanas que lo integran, junto con unidades de Untikesken, es un semis $-R R C$ 196/2- de solo 6,32 g de peso (Villaronga, 1993: n. 182). No obstante, los testimonios más numerosos $y$, por tanto, representativos no se apartan del mencionado perfil colector, como vemos en otro de los hallazgos ampuritanos ( $R R C H$ 136; Villaronga, 1993: n. 181) y su entorno -Alt Empordà- (Villaronga, 1993: n. 169), donde los bronces de Untikesken, casi siempre mayoritarios, son unidades cuyo peso y módulo -c. 21-22 g y 30-32 mm- no desentona demasiado con la metrología de los ases romanos emitidos en un momento ya avanzado del s. II a. C. (Bransbourg, 2011: 111, fig. 1).

Un caso excepcional, no solo por su número y procedencia, sino también por su composición, es el ocultamiento de Torelló d'en Cintes (Mahón, Menorca) (RRCH $A D$ 24; Villaronga, 1993: n. 192). Dejando a un lado la exótica moneda de Populonia, la interesante reacunación de un as romano sobre una unidad de Obulco (Arévalo González y Marcos Alonso, 1998: 26-28) y la inclusión de una unidad de Untikesken, parece clara la intención de su poseedor de extraer de la circulación -presumiblemente local- ases romano-republicanos, esto es, moneda oficial romana, pero también ejemplares de peso y módulo elevados. Se deben incluir, no obstante, en este criterio de selección metrológica dos de los tres divisores que formaban parte del conjunto: el sextans de Populonia (16 g) y un semis romano, la moneda más antigua de las identificadas en el conjunto y, por tanto, de peso todavía elevado (25,02 g) (Arévalo González y Marcos Alonso, 1998: 39), por lo que solo destaca en este hallazgo por su reducido módulo y escaso peso $(7,79 \mathrm{~g}$ y $20,8 \mathrm{~mm})$ un sextans romano. Debe anotarse que estas anomalías, en cuanto al criterio de selección metrológica se refiere, parecen decantarse hacia la moneda romana, la oficial, y presumiblemente la de mayor prestigio como comentaremos más adelante. 

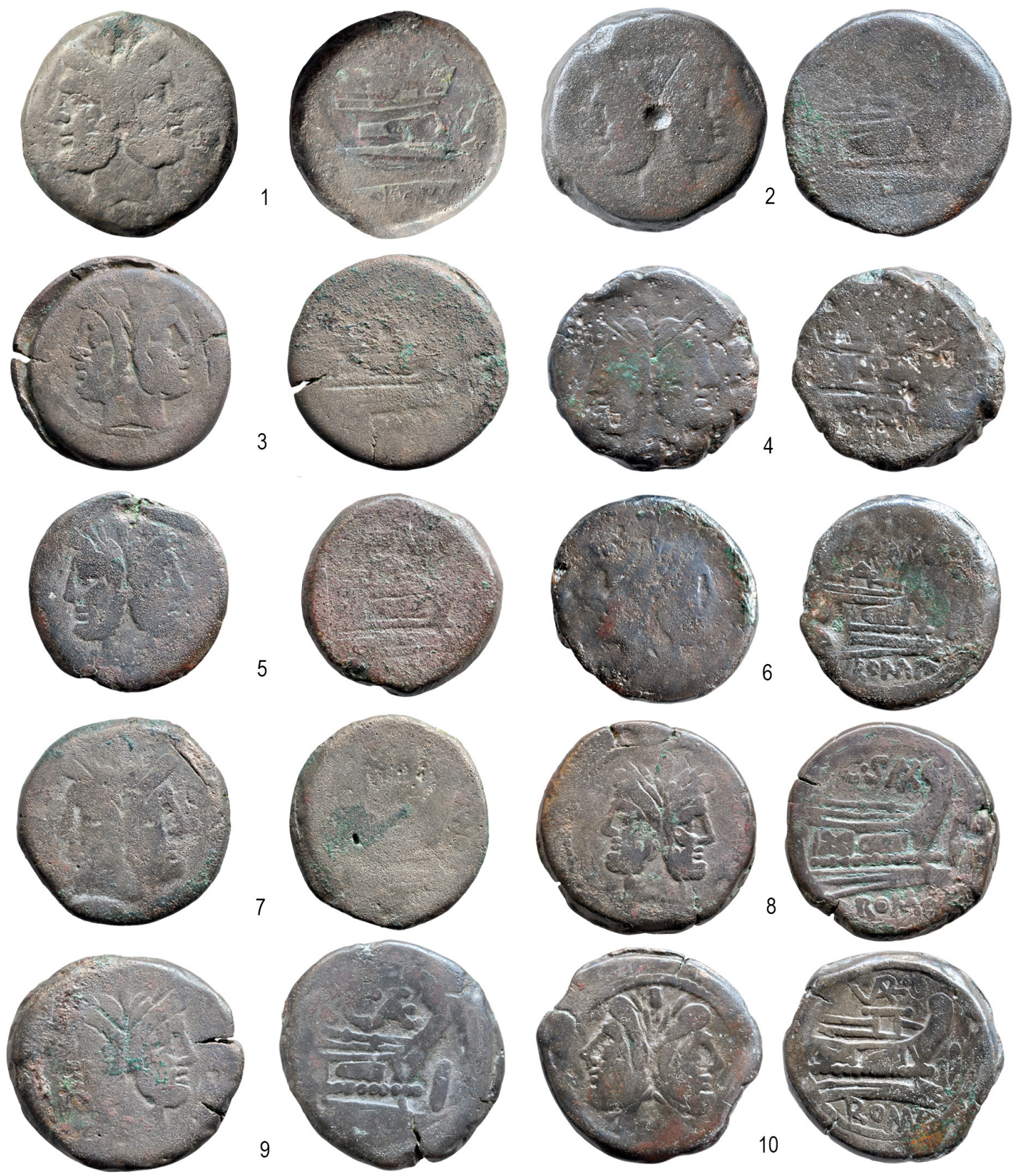

FIG. 4. Monedas recuperadas en el depósito de la Torre de Benagalbón.

Aunque su cierre, situado a principios del s. I a. C. por la data defendida para la mencionada reacuńación romana sobre una unidad de Obulco y, sobre todo, por la presencia de un as $R R C 296 / 2$ del 112-111 a. C. (Arévalo y Marcos, 1998: 21), se aleja del propuesto para los ocultamientos surhispanos -incluido como veremos el de Benagalbón- a lo largo de la segunda mitad del s. II a. C., el conjunto de ases romanos de Torelló supone, con las salvedades propias de la circulación monetaria insular, una importante aportación al conocimiento de la circulación monetaria de estos nominales en Hispania. 

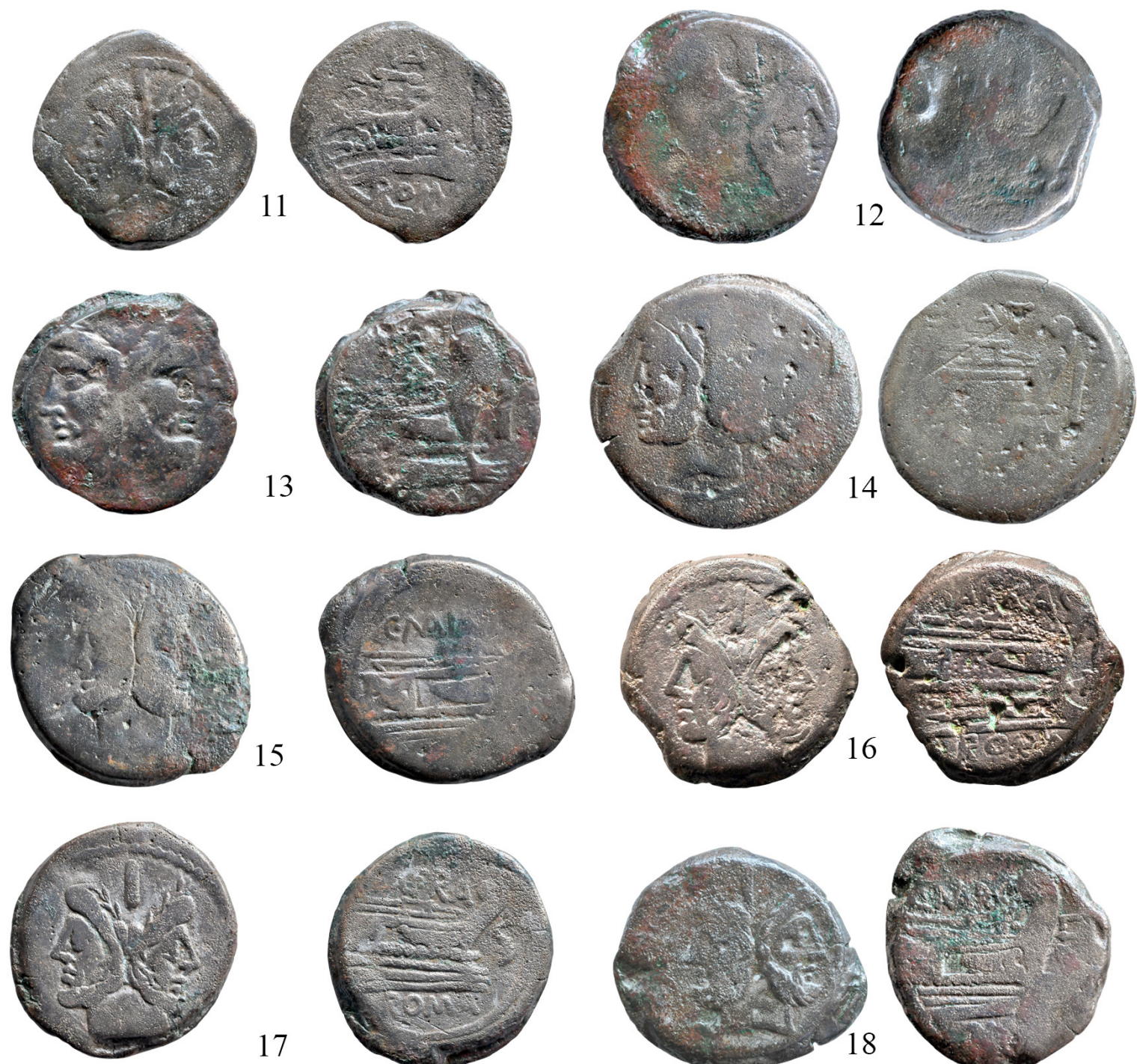

17
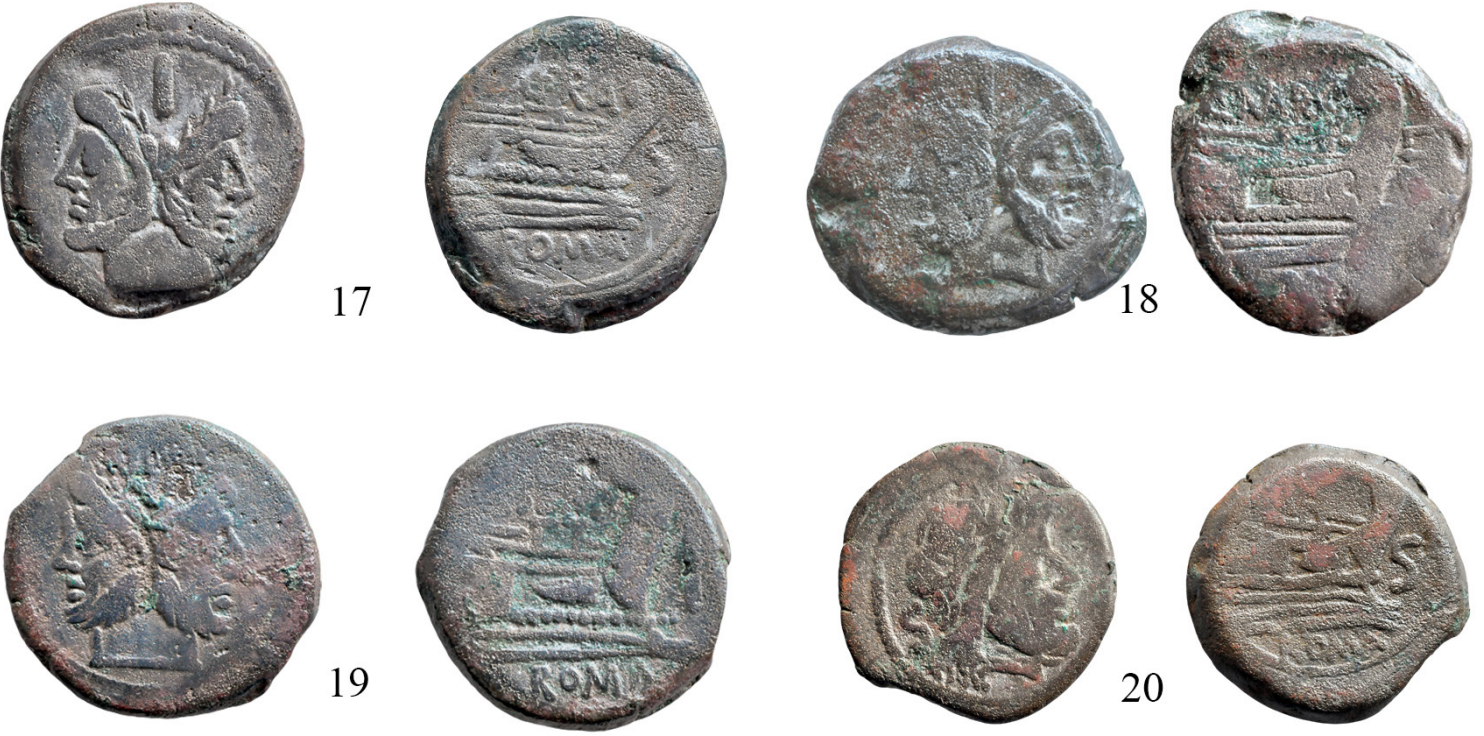

FIG. 4. Monedas recuperadas en el depósito de la Torre de Benagalbón (cont.).

El conjunto de Torelló, junto con otros hallazgos de circulación como Cáceres el Viejo y los campamentos numantinos, entre otros, permite valorar mejor la presencia de las emisiones de ases romano-republicanos documentadas en ocultamientos con un menor número de ejemplares. Los estudios 
180 B. Mora y A. Pérez / Un nuevo ocultamiento monetario de bronces romano-republicanos y de Castulo en el sur ...
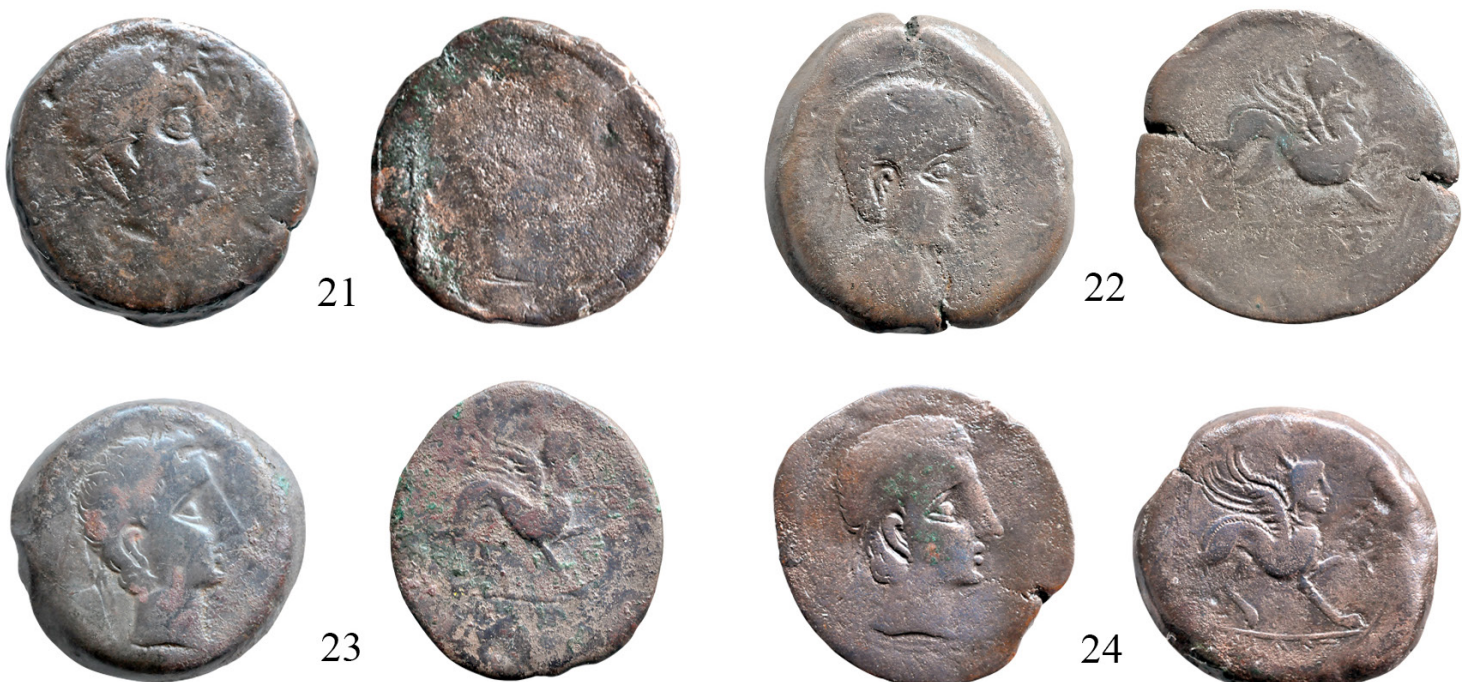

23
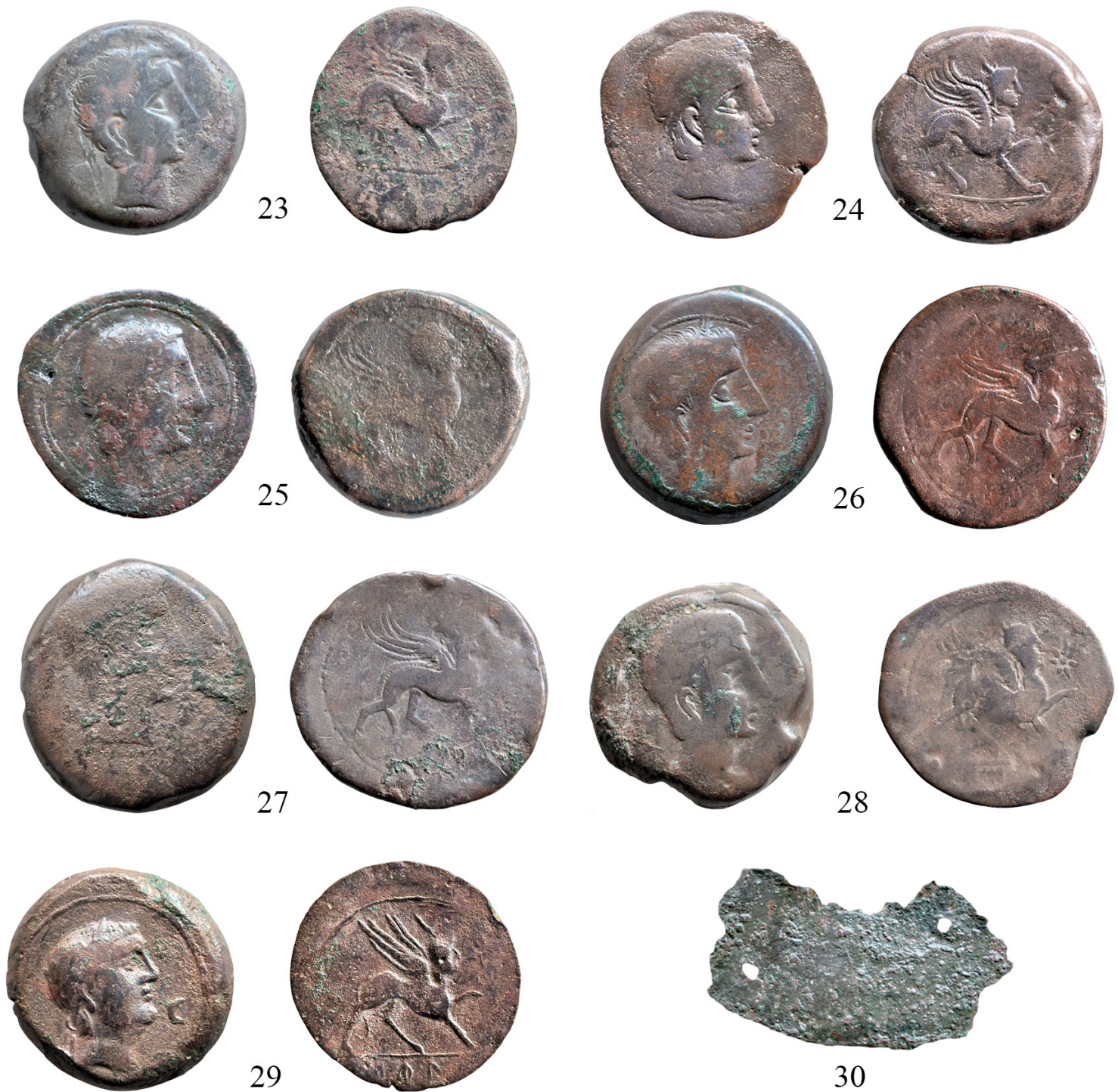

FIG. 4. Monedas recuperadas en el depósito de la Torre de Benagalbón (cont.).

de conjunto de Ripollès (1982), Arévalo y Marcos (1998: 43-65) para la Tarraconense, y el más reciente de Ruiz López (2010) para el mediodía hispano, son de gran ayuda para un análisis de conjunto, mientras 
que la muy útil recopilación de A. $\mathrm{McCabe}^{7}$, con el actualizado índice de rareza de las emisiones de bronce romano-republicanas, nos proporciona un útil marco comparativo para valorar presencias y ausencias en la circulación monetaria hispana y, sobre todo, en los territorios meridionales, donde debieron formarse los ocultamientos de bronces que comentamos.

A esta recopilación (Fig. 5), que no pretende ser exhaustiva, se han incorporado referencias a hallazgos hispanos bien identificados, distinguiendo entre los procedentes de ocultamientos, aislados y -como puntual complemento- también algunas colecciones señeras, pero sin procedencia segura aunque de probable origen local o regional, como la de la Real Academia de la Historia (Chaves, 2005: 17-19), entre otras.

Como observación general cabe destacar que, salvo algunos casos, el grueso de los bronces romanos documentados forma parte de emisiones 'comunes' y por tanto no es extraño que estén bien documentadas en hallazgos aislados y, especialmente, en ocultamientos con un considerable número de monedas como el de Torelló. Sus 383 ases proporcionan, en consonancia con otros hallazgos similares no peninsulares como el de Motoro Inferiore $(R R C H 143)^{8}$, una interesante aproximación a la composición de los ocultamientos andaluces y, en concreto, al malacitano. Así, asumiendo la presencia de algún ejemplar de producción muy escasa y por tanto de hallazgo infrecuente $-\mathrm{n} .^{\circ}$ 7, RRC 149/1, no obstante, de insegura atribución-, el mayor número de coincidencias se produce en las emisiones datadas en los ańos centrales del s. II a. C.

Los ejemplares $R R C 215 / 2$ y $216 / 2$ (n. ${ }^{\text {os }} 18-19$ ) marcan un punto de inflexión en el aprovisionamiento de bronce romano en Hispania; siendo la de Q. Marcius Libo todavía frecuente como se deduce de su buena representación en Torelló -9 monedas-

McCabe, A.: Rarity Estimate-Roman Republican Bronzes. http://andrewmccabe.ancients.info/RomanRepublicBronzeRarities.html [acceso 15/11/2016].

8 Un interesante complemento en la consulta de estos hallazgos es CHRR $=$ Coin Horads of the Roman Republic Online. http://numismatics.org/chrr/ [acceso 23/12/2016]. $\mathrm{y}$ en diversos yacimientos, e incluso en alguna colección pública sin procedencia segura. Por el contrario, el ejemplar de L. Sempronius Pitio está peor documentado en Torelló -3 monedas-, aunque con el mismo número de ejemplares que en el ocultamiento de Montoro Inferiore. La emisión siguiente de C. Terentius Lucanus -RRC 217/2-, presente ya solo en el ocultamiento de El Saucejo y en el italiano ya mencionado, con un único ejemplar en ambos casos, debía ser más escasa en el sur peninsular y no debe sorprender su ausencia en el ocultamiento de Benagalbón, aunque está documentada en otros hallazgos hispanos como Vall d'Uxo, La Torre d'Onda y Los Villares. Por último, la emisión $R R C$ 219/2 marca la brusca interrupción del aprovisionamiento regular de ases procedentes de la ceca de Roma como lo demuestra no solo el brusco descenso de hallazgos de la emisión a nombre de C. Antesti[us], sino también su hallazgo en el campamento de Cáceres el Viejo, cuya cronología justifica la presencia de emisiones más tardías y de reducido volumen?.

Además, el ocultamiento de Benagalbón ofrece otras particularidades que merecen ser destacadas. La primera es la presencia de un bronce anónimo ${ }^{10}$, un as, pero sobre todo sobresale la inclusión de un semis, nominal muy poco frecuente en los hallazgos hispanos de similares características. El primero (n. ${ }^{\circ}$ 12) se corresponde con la serie anónima encuadrable en el grupo K1 de McCabe (2013: 197-199). En cuanto al semis (n. ${ }^{\circ} 20$ ), seguramente encuadrable en la serie del magistrado Opeimius (RRC 188/2), es una novedad en los ocultamientos surhispanos con moneda de bronce romana, aunque dentro de su rareza no faltan paralelos para la inclusión de divisores romanos en otros ocultamientos como los ya citados de Ampurias (un semis RRC 196/2) y Torelló (un semis n. 1 y un sextans n. 385). Lo que cabe destacar del hallazgo de Benagalbón es que no se

9 Puede ser relevante la presencia de un as de la misma emisión en los fondos del Museo Nacional de Arte Romano de Mérida; $c f$. Ruiz López, 2010: 1174.

10 De los 5 primeros ejemplares catalogados, probablemente alguno pertenezca a series con nombres de magistrado o símbolos, que no se aprecian por su desgaste o deterioro. 
182 B. Mora y A. Pérez / Un nuevo ocultamiento monetario de bronces romano-republicanos y de Castulo en el sur ...

\begin{tabular}{|c|c|c|c|c|c|c|c|c|c|}
\hline$R R C$ & $\begin{array}{c}\text { Cronología } \\
\text { (a. C.) }\end{array}$ & EMISIÓN & VALOR & BeNaGalbón & $\begin{array}{c}\text { Otros } \\
\text { Ocultamientos }\end{array}$ & $\begin{array}{c}\text { HALLAZGOS } \\
\text { HISPANOS }\end{array}$ & $\begin{array}{c}\text { COLECCIONES } \\
\text { HISPANAS } \\
\end{array}$ & $\begin{array}{l}\text { MonTORO } \\
\text { INF. }\end{array}$ & $\begin{array}{l}\text { RAREZA } \\
\text { McCABE }\end{array}$ \\
\hline $113 / 2$ & 206-195 & estrella & as & & & 1 El Penedés & $1 \mathrm{RAH}$ & & $\begin{array}{l}\text { Very } \\
\text { Scarce }\end{array}$ \\
\hline $114 / 2$ & $206-195$ & rostrum & as & & & & & & Common \\
\hline $116 / 2$ & $206-195$ & toro & as & & & & & & $\begin{array}{l}\text { Extremely } \\
\text { Rare }\end{array}$ \\
\hline $117 \mathrm{~B} / 1$ & $206-195$ & pájaro y timón & as & & 1 Torelló & 2 Numancia & & & Common \\
\hline $118 / 1$ & $206-195$ & casco & as & & 1 Torelló & & & & Scarce \\
\hline $119 / 3$ & $206-195$ & fulmen & as & & & & & & $\begin{array}{l}\text { Very } \\
\text { Scarce }\end{array}$ \\
\hline $120 / 3$ & $206-195$ & cuchillo & as & & 1 Torelló & & & & $\begin{array}{l}\text { Very } \\
\text { Scarce }\end{array}$ \\
\hline $121 / 3$ & $206-195$ & cerdo & as & & & & & 1 & $\begin{array}{l}\text { Very } \\
\text { Scarce }\end{array}$ \\
\hline $122 / 3$ & $206-195$ & perro & as & & 1 Torelló & 1 Numancia & & & Scarce \\
\hline $123 / 2$ & $206-195$ & carnero & as & & & & & & $\begin{array}{l}\text { Extremely } \\
\text { Rare }\end{array}$ \\
\hline $124 / 3$ & $206-195$ & meta & as & & $\begin{array}{l}3 \text { Torelló: } \\
1 \text { Azaila II }\end{array}$ & $\begin{array}{l}1 \text { Numancia; } \\
1 \text { La Carencia }\end{array}$ & $1 \mathrm{RAH}$ & & Scarce \\
\hline $132 / 3$ & $194-190$ & $\mathrm{ME}$ & as & & & 1 Numancia & $1 \mathrm{RAH}$ & & Scarce \\
\hline $133 / 4$ & $194-190$ & TAMP & as & & & & $1 \mathrm{RAH}$ & & Scarce \\
\hline $134 / 2$ & $194-190$ & LPLH & as & & $\begin{array}{l}1 \text { El Saucejo; } \\
\text { 2 Torelló }\end{array}$ & 1 Numancia & 1 Alcoy & & Scarce \\
\hline $136 / 2$ & $194-190$ & $\mathrm{AN}$ & as & & & 2 Ampurias & & & $\begin{array}{l}\text { Very } \\
\text { Scarce }\end{array}$ \\
\hline $137 / 2$ & $194-190$ & creciente & as & & 1 Torelló & 1 Numancia & & & $\begin{array}{l}\text { Very } \\
\text { Scarce }\end{array}$ \\
\hline $141 / 2$ & $189-180$ & pájaro TOD & as & & 1 Torelló & 1 Numancia & & 1 & Scarce \\
\hline $142 / 1$ & $189-180$ & toro $\mathrm{MD}$ & as & 1 & 2 Torelló & 1 Castra Caecilia & & 1 & Common \\
\hline $143 / 1$ & $189-180$ & escudo MAE & as & & & 1 Numancia & & & $\begin{array}{l}\text { Very } \\
\text { Scarce }\end{array}$ \\
\hline $144 / 1$ & $189-180$ & Victoria LPF & as & & 2 Torelló & & & & Common \\
\hline $145 / 1$ & $189-180$ & $\begin{array}{l}\text { Victoria y } \\
\text { punta de lanza }\end{array}$ & as & & 4 Torelló & & $1 \mathrm{RAH}$ & 1 & Common \\
\hline $147 / 2$ & $189-180$ & CN DOM & as & & 1 Torelló & & & & Rare \\
\hline $148 / 1$ & $189-180$ & Q MARI & as & & & & & & $\begin{array}{l}\text { Very } \\
\text { Scarce }\end{array}$ \\
\hline $149 / 1$ & $189-180$ & \begin{tabular}{|l} 
L. MAMILI ULISES \\
\end{tabular} & as & 1 & & & & & $\begin{array}{l}\text { Very } \\
\text { Scarce }\end{array}$ \\
\hline $150 / 1$ & $189-180$ & M. TITINI & as & & 1 Torelló & $\begin{array}{c}1 \text { Hornachuelos } \\
1 \text { Coll. Jardines } \\
1 \text { Ampurias }\end{array}$ & $1 \mathrm{RAH}$ & 1 & Scarce \\
\hline $151 / v$ & $189-180$ & S. FV & as & & & & & & $\begin{array}{l}\text { Extremely } \\
\text { Rare }\end{array}$ \\
\hline $155 / 2$ & $179-170$ & PVR & as & & & & & & Very Rare \\
\hline $156 / 3$ & $179-170$ & gamba & as & & & & & & Very Rare \\
\hline $159 / 3$ & $179-170$ & mosca & as & & 1 Torelló & & & & Scarce \\
\hline $160 / 1$ & $179-170$ & delfín & as & & 1 Torelló & 1 Castra Caecilia & & & Scarce \\
\hline
\end{tabular}

Fig. 5. Bronce romano del s. II a. C. documentado en hallazgos hispanos. Abreviaturas utilizadas: MAP = Museo Arqueológico Provincial; $M C=$ Museo Comarcal; $M N A R=$ Museo Nacional de Arte Romano, Mérida $;$ RAH = Real Academia de la Historia, Madrid; T. = Tesoro. 


\begin{tabular}{|c|c|c|c|c|c|c|c|c|c|}
\hline$R R C$ & $\begin{array}{c}\text { Cronología } \\
\text { (a. C.) }\end{array}$ & EMISIÓN & VALOR & BENAGALBÓN & $\begin{array}{c}\text { Otros } \\
\text { OCULTAMIENTOS }\end{array}$ & $\begin{array}{c}\text { HALLAZGOS } \\
\text { HISPANOS }\end{array}$ & $\begin{array}{c}\text { COLECCIONES } \\
\text { HISPANAS } \\
\end{array}$ & $\begin{array}{c}\text { MONTORO } \\
\text { INF. }\end{array}$ & $\begin{array}{c}\text { RAREZA } \\
\text { McCABE } \\
\end{array}$ \\
\hline $161 / 2$ & $179-170$ & TAL & as & & & 1 Numancia & & & Very Rare \\
\hline $162 / 3$ & $179-170$ & MAT & as & & $\begin{array}{c}1 \text { Écija-T. } \\
1 \text { Castillejos II } \\
\text { 4 Torelló } \\
\end{array}$ & $\begin{array}{l}1 \text { Hornachuelos } \\
1 \text { Castellón } \\
1 \text { Menorca }\end{array}$ & $1 \mathrm{RAH}$ & & Common \\
\hline $172 / 2$ & $199-170$ & MA & as & & & 3 Pico de los Ajos & 1 MAP Tarrag. & & $\begin{array}{l}\text { Extremely } \\
\text { Rare }\end{array}$ \\
\hline $173 / 1$ & $169-158$ & C. SAX & as & 1 & 2 Torelló & & $1 \mathrm{RAH}$ & 1 & Common \\
\hline $174 / 1$ & $169-158$ & A. $C A E$ & as & 1 & 1 Torelló & $\begin{array}{c}1 \text { Castra Caecilia } \\
1 \text { Los Villares }\end{array}$ & $1 \mathrm{RAH}$ & 2 & Common \\
\hline $176 / 1$ & $169-158$ & PAE & as & & 1 Torelló & 1 Ampurias & $1 \mathrm{RAH}$ & & Common \\
\hline $177 / 1$ & $169-158$ & PT & as & & 23 Torelló & 1 Hornachuelos & & 1 & Common \\
\hline $178 / 1$ & $169-158$ & CINA & as & & 4 Torelló & & 1 MAP Girona & 2 & Common \\
\hline $179 / 1$ & $169-158$ & BAL & as & & & $\begin{array}{c}1 \text { Hornachuelos } \\
1 \text { Xarpolar }\end{array}$ & $1 \mathrm{RAH}$ & 1 & Common \\
\hline $180 / 1$ & $169-158$ & $\operatorname{SAX}$ & as & & 2Torelló & $\begin{array}{c}1 \text { Castra Caecilia } \\
1 \text { El Rabat } \\
1 \text { Los Villares } \\
\end{array}$ & $2 \mathrm{RAH}$ & 1 & Common \\
\hline $181 / 1$ & $169-158$ & pilei & as & & & & & & Scarce \\
\hline $182 / 2$ & $169-158$ & $\begin{array}{l}\text { grifo, cabeza de } \\
\text { liebre }\end{array}$ & as & & $\begin{array}{c}1 \text { El Saucejo } \\
1 \text { Castillejos II }\end{array}$ & 1 Castra Caecilia & $1 \mathrm{RAH}$ & 2 & Common \\
\hline $183 / 1$ & $169-158$ & loba y gemelos & as & & $\begin{array}{l}1 \text { Écija-T. } \\
\text { 3 Torelló }\end{array}$ & \multicolumn{2}{|l|}{$\begin{array}{l}1 \text { Numancia } \\
1 \text { Ampurias }\end{array}$} & 3 & Common \\
\hline $184 / 1$ & $169-158$ & mariposa y vid & as & & 17 Torelló & 2 Numancia & & 2 & Common \\
\hline $185 / 1$ & $169-158$ & \begin{tabular}{|l} 
VARO \\
\end{tabular} & as & 1 & 5 Torelló & & & & Common \\
\hline $186 / 1$ & $169-158$ & MVRENA & as & & 8 Torelló & $\begin{array}{l}1 \text { Cabeço de } \\
\text { Mariola } \\
1 \text { Ampurias }\end{array}$ & & 2 & Common \\
\hline $186 / \mathrm{Av}$ & $169-158$ & MVR & as & & & & & & Extremely Rare \\
\hline $187 / 2$ & $169-158$ & PVR & as & & & 2 Pico de los Ajos & $1 \mathrm{RAH}$ & 1 & Scarce \\
\hline $188 / 1$ & $169-158$ & OPEIMI & as & & & & & & Common \\
\hline $188 / 2$ & $169-158$ & OPEIMI & semis & 1 & & & & & Very Rave \\
\hline $189 / 1$ & $169-158$ & P.BLAS & as & & 4Torelló & & 1 MNAR & 4 & Common \\
\hline $190 / 1$ & $169-158$ & OPEI & as & & 6 Torelló & $\begin{array}{c}1 \text { Tivisa } \\
1 \text { Numancia } \\
1 \text { Menorca } \\
\end{array}$ & $2 \mathrm{RAH}$ & 2 & Common \\
\hline $191 / 1$ & $169-158$ & VAL & as & 1 & 4 Torelló & $\begin{array}{l}1 \text { Ampurias } \\
1 \text { Ullastret }\end{array}$ & $\begin{array}{l}1 \text { MNAR 24,65 g } \\
1 \text { MAP Girona } \\
1 \text { M Menorca }\end{array}$ & 2 & Common \\
\hline & & & & & & & & & Common \\
\hline $193 / 1$ & $169-158$ & TVRD & as & & 11 Torelló & $\begin{array}{c}1 \text { Castra Caecilia } \\
2 \text { Numancia }\end{array}$ & $\begin{array}{c}1 \mathrm{RAH} \\
1 \mathrm{MNAR} \\
\end{array}$ & 2 & Common \\
\hline $194 / 1$ & $169-158$ & ancla & as & & 7 Torelló & $\begin{array}{c}1 \text { Segaria } \\
1 \text { Los Vilares } \\
\end{array}$ & 1 Mc Manresa & & Common \\
\hline $195 / 1$ & 169-158 & asno & as & & 6 Torelló & 1 Numancia & & 1 & Common \\
\hline $196 / 1$ & $169-158$ & estrella & as & & $\begin{array}{l}1 \text { Écija-T. } \\
6 \text { Torelló }\end{array}$ & & $1 \mathrm{RAH}$ & & Common \\
\hline 198B/1a & $157-156$ & $\begin{array}{l}\text { anónimo I } \\
\text { delante de proa }\end{array}$ & as & & 10 Torelló & & & & \begin{tabular}{|l} 
Very \\
Scarce \\
\end{tabular} \\
\hline
\end{tabular}

FIG. 5. Bronce romano del s. II a. C. documentado en hallazgos hispanos (cont.). 
184 B. Mora y A. Pérez / Un nuevo ocultamiento monetario de bronces romano-republicanos y de Castulo en el sur ...

\begin{tabular}{|c|c|c|c|c|c|c|c|c|c|}
\hline$R R C$ & $\begin{array}{c}\text { Cronología } \\
\text { (a. C.) }\end{array}$ & EMISIÓN & VALOR & BENAGALBÓN & $\begin{array}{c}\text { Otros } \\
\text { Ocultamientos }\end{array}$ & $\begin{array}{c}\text { HALLAZGOS } \\
\text { HISPANOS }\end{array}$ & $\begin{array}{c}\text { COLECCIONES } \\
\text { HISPANAS }\end{array}$ & $\begin{array}{c}\text { MONTORO } \\
\text { INF. }\end{array}$ & $\begin{array}{l}\text { RAREZA } \\
\text { McCABE }\end{array}$ \\
\hline $198 \mathrm{~B} / \mathrm{lb}$ & $157-156$ & $\begin{array}{l}\text { anónimo I } \\
\text { sobre proa }\end{array}$ & as & 1 & 58 Torelló & $\begin{array}{l}4 \text { Numancia } \\
1 \text { Los Villares }\end{array}$ & & & \\
\hline $199 / 2$ & 155 & SAR & as & & $\begin{array}{l}1 \text { El Saucejo } \\
2 \text { Torelló }\end{array}$ & 1 Pico de los Ajos & $1 \mathrm{RAH}$ & & Common \\
\hline $200 / 2$ & 155 & NAT & as & 1 & 5Torelló & $\begin{array}{c}1 \text { Castra Caecilia } \\
1 \text { Los Villares }\end{array}$ & $1 \mathrm{RAH}$ & 2 & Common \\
\hline $201 / 2$ & 154 & C. SCR & as & & $\begin{array}{c}1 \text { Castillejos II } \\
2 \text { Torelló }\end{array}$ & & & 2 & Common \\
\hline $203 / 2$ & 153 & C. MAIANI & as & 1 & $\begin{array}{c}1 \text { Écija-T. } 17,72 \mathrm{~g} \\
\text { 4 Torelló }\end{array}$ & 1 (Ampurias) & $1 \mathrm{RAH}$ & 6 & Common \\
\hline $204 / 2$ & 152 & L. SAVF & as & & $\begin{array}{l}6 \text { Torelló } \\
1 \text { Azaila II }\end{array}$ & $\begin{array}{l}1 \text { Menorca; } \\
1 \text { Los Villares }\end{array}$ & $1 \mathrm{RAH}$ & 6 & Common \\
\hline $205 / 2$ & 151 & P. SVLA & as & & $\begin{array}{l}1 \text { Écija-T. } \\
3 \text { Torelló }\end{array}$ & 1 Sa Pleta & $2 \mathrm{RAH}$ & 4 & Common \\
\hline $206 / 2$ & 150 & SAFRA & as & 2 & 5 Torelló & & 1 MAP Girona & 1 & Common \\
\hline $210 / 2$ & 149 & C. IVNI C.F. & as & & 8 Torelló & $\begin{array}{c}1 \text { Castra Caecilia } \\
1 \text { Valencia }\end{array}$ & & 1 & Common \\
\hline $211 / 1$ & $155-149$ & Q.ME & as & & & & & & Very Rare \\
\hline $212 / 1$ & $155-149$ & creciente & as & & 1 Torelló & & & & Very Rare \\
\hline $213 / 1$ & $155-149$ & mástil y vela & as & & & & & & Scarce \\
\hline $214 / 2$ & 148 & M. ATILISARAN & as & & 12 Torelló & $\begin{array}{c}1 \text { Cabezo Agudo } \\
2 \text { Ampurias } \\
1 \text { Menorca }\end{array}$ & & 2 & Common \\
\hline $215 / 2$ & 148 & Q.MARC LIBO & as & 1 & 9 Torelló & $\begin{array}{l}1 \text { Castra Caecilia } \\
1 \text { Ampurias } \\
1 \text { El Penedés } \\
1 \text { El Rabat } \\
1 \text { Los Villares } \\
\end{array}$ & $1 \mathrm{RAH}$ & 1 & Common \\
\hline $216 / 2$ & 148 & L.SEMPR PITIO & as & 1 & 3 Torelló & & & 3 & Common \\
\hline $217 / 2$ & 147 & C.TER LVC & as & & 1 El Saucejo & $\begin{array}{c}1 \text { Vall d'Uixó } \\
1 \text { La Torre d'Onda } \\
1 \text { Los Villares }\end{array}$ & & 1 & Common \\
\hline $219 / 2$ & 146 & C.ANTESTI & as & & & 1 Castra Caecilia & $\begin{array}{l}1 \text { MNAR } \\
1 \text { Alcoy }\end{array}$ & & Scarce \\
\hline $219 / 3$ & & C.ANTESTI & semis & & & & & & $\begin{array}{l}\text { Very } \\
\text { Scarce }\end{array}$ \\
\hline
\end{tabular}

FIG. 5. Bronce romano del s. II a. C. documentado en hallazgos hispanos (cont.).

trata de la moneda que cierra el conjunto o, al menos, una de las de cronología más reciente, sino que se inserta en el subgrupo más numeroso del ocultamiento formado por emisiones datadas entre el 160 y 150 a. C. Su peso y módulo $-17,7$ g y $26,6 \mathrm{~mm}-$ es cierto que no se alejan demasiado de los ases más ligeros con c. 20-23 g y $30 \mathrm{~mm}$, pero si incluimos los ejemplares de Castulo y, sobre todo, los ases republicanos inclasificables por su elevado desgaste, la distancia metrológica resulta algo más acusada.
A pesar de la falta de indicios cronológicos que nos proporciona el contexto arqueológico de este hallazgo monetario, tanto en lo que respecta a los restos del contenedor cerámico que lo protegía como a las estructuras entre las que fue descubierto, sensiblemente alteradas como se ha visto por la construcción de las dependencias de las termas pertenecientes a la villa altoimperial, la ausencia de moneda romana posterior al 148 a. C., unido al moderado - pero evidente- grado de desgaste de 
los ases romano-republicanos más recientes ${ }^{11}$, aconseja una posible data para la ocultación monetaria de Benagalbón en los años finales del s. II a. C. Un marco cronológico algo más reciente que el propuesto para los ocultamientos de El Saucejo y Écija pues, aunque ofrecen una posible fecha de cierre cercana al nuestro -según la moneda romana, entre el 151 y el 147 a. C.-, su desgaste es menos acusado. Un caso parecido es el de Castillejos II, pues si bien su as más moderno se data en 154 a. C., su considerable desgaste plantea retrasar su cierre hasta los años finales del s. II a. C. (Conejo, 2014: 19) ${ }^{12}$.

No obstante, estas deducciones cronológicas, creemos que razonables, suponen insistir para estos ańos finales del s. II a. C. en el ya recalcado criterio selectivo, a favor de ases o unidades de peso y módulo elevados, que prima en los ocultamientos hispanos de moneda de bronce datados con anterioridad al s. I a. C. No puede descartarse, por tanto, que las abundantes emisiones de divisores del as, especialmente semis, de $c$. 130-127 a. C., fueran conocidas - a la vez que descartadas- por los responsables de los ocultamientos de El Saucejo, Castillejos II y Benagalbón. Un repaso a los hallazgos conocidos de estas emisiones en suelo hispano parece mostrar que su circulación fue muy escasa (Ruiz López, 2010: 1422 y 1434$)$.

11 Grado de desgaste y conservación de las monedas, especialmente en aquellos casos en los que son sometidas a necesarios procesos de restauración, deben ser tenidos en cuenta a la hora de proponer una data aproximada de cierre para un determinado ocultamiento, como es nuestro caso. En cualquier caso, llama la atención que en nuestro caso no pueda hacerse una lectura lineal del desgaste de las monedas, como se deduce, por ejemplo, de la comparación de los ejemplares n. ${ }^{\text {os }} 10$ (Varo) y 18 (Libo).

12 Llevarlo hasta inicios del s. I a. C. parece menos probable, en función de los argumentos que venimos exponiendo. Se asumen pues los límites cronológicos propuestos en su día por Chaves (1991-1993: 268), en función de la excesivamente compartimentada periodización general de Crawford para el caso hispano, aunque contemplando también la inclusión de subgrupos como el que aquí se apunta, anterior a las primeras décadas del s. I a. C. En este sentido cabe recordar la posible incidencia de particularidades regionales en la circulación monetaria preimperial, y su repercusión en los tesorillos y ocultamientos; $c f$. Campo, 1982: 65.
Pero la discusión de la data más probable para el cierre de este ocultamiento monetario de Benagalbón presenta otra variable al tratarse de un hallazgo de composición mixta, romana e hispana, en concreto de Castulo (Cazlona, Jaén). La cronología propuesta para las emisiones documentadas, así como su grado de desgaste, son datos que deben ser tenidos en cuenta, a pesar de que el considerable margen cronológico en el que se datan las emisiones locales hispanas no suele aportar información precisa sobre este importante asunto (García-Bellido y Blázquez Cerrato, 2001: 118).

Asumiendo las dataciones de la ceca oretana a partir del estudio monográfico de García-Bellido ${ }^{13}$, las emisiones castulonenses presentes en el ocultamiento malacitano se reparten en dos grandes grupos. Por un lado, y dejando a un lado la difícil identificación de la moneda n. ${ }^{\circ} 21$, que podría pertenecer a la Serie III, contamos con cuatro unidades de la Serie iv de García-Bellido (n. $\left.{ }^{\text {os }} 22-25\right)$. Su data más antigua -c. 179-165 a. C. (García-Bellido, 1982: 200-201) - se muestra acorde con su mayor desgaste, con la excepción del ejemplar perteneciente a la Serie ivb -símbolo delfín- que posiblemente se corresponda con las producciones más recientes de este grupo y cercanas, por tanto, a los cuatro ejemplares de la Serie v, tres con símbolo mano -va-y solo uno con símbolo creciente -vb-.

La data propuesta para esta serie $-c$. 165-80 a. C. (García-Bellido, 1982: 206-207)- encaja con la cronología y desgaste que proporcionan los ases romanos más recientes, $c .148$ a. C. No obstante, el buen estado de conservación del ejemplar n. ${ }^{\circ}$ 29, perteneciente a la Serie vb con símbolo creciente, plantea la posibilidad de que nuestro ocultamiento se cerrara con moneda local; siendo por tanto necesario afinar todo lo posible la datación de este grupo y, en consecuencia, su posición en

13 No obstante, un corpora de referencia como el de Villaronga, en su más reciente edición, acorta los años de emisión de algunas series como es el caso de la vb -creciente- en los años cincuenta del s. II a. C. (Villaronga y Benages, 2011: 412-415). Debe recordarse, en este sentido, que García-Bellido (1982: 210) ya había propuesto retrasar el inicio de esta serie hasta el 150 a. C. 


\begin{tabular}{|c|c|c|c|c|c|}
\hline $\begin{array}{c}\text { LUGaR/ } \\
\text { DenOMINACIÓN }\end{array}$ & $\begin{array}{l}\text { Cronología } \\
\text { (a. C.) }\end{array}$ & $\begin{array}{c}\text { MONEDA } \\
\text { ROM.-REPUB. } \\
(R R C)\end{array}$ & & $\begin{array}{l}\text { MONEDA } \\
\text { HISPANA }\end{array}$ & $\mathrm{N} .^{\mathrm{o}}$ \\
\hline \multirow{7}{*}{$\begin{array}{l}\text { Écija } 1979 \\
\text { Vill.179, RRCHAD } 17\end{array}$} & $195-179$ & & & C Castulo s. III & 5 \\
\hline & post 211 & & frustros & & 4 \\
\hline & $179-170$ & $162 / 3$ & MAT & & 1 \\
\hline & $169-158$ & $183 / 1$ & loba y gemelos & & 1 \\
\hline & $169-158$ & $196 / 1$ & estrella & & 1 \\
\hline & 153 & $203 / 2$ & MAIANI & & 1 \\
\hline & 151 & $205 / 2$ & P.SVLA & Carmo s. I & 1 \\
\hline \multirow{4}{*}{$\begin{array}{l}\text { El Saucejo } R R C H 18 \\
\text { Vill. } 180\end{array}$} & 194-190 & $134 / 2$ & LPLH & Castulo s. III ko & $1+1$ \\
\hline & $169-158$ & $182 / 2$ & $\begin{array}{l}\text { grifo y cab. } \\
\text { liebre }\end{array}$ & & 1 \\
\hline & 155 & $199 / 2$ & SAR & Urso s. I & $1+1$ \\
\hline & 147 & $217 / 2$ & C.TER $\cdot$ LVC & Carmo s. I & $1+3$ \\
\hline \multirow{16}{*}{ Benagalbón } & post 211 & & frustros & & 5 \\
\hline & $195-165$ & & & Castulo ¿̨III/IV? & 1 \\
\hline & $189-180$ & $142 / 1$ & toro y $\mathrm{MD}$ & & 1 \\
\hline & $189-180$ & $149 / 1 \mathrm{a}$ & Roma del. proa & Castulo Iva & $1+3$ \\
\hline & $169-158$ & $173 / 1$ & $C \cdot S A X$ & Castulo Ivb & 1 \\
\hline & $169-158$ & $174 / 1$ & $\mathrm{~A} \cdot \mathrm{CAE}$ & & 1 \\
\hline & $169-158$ & $185 / 1$ & VARO & & 1 \\
\hline & $169-158$ & $188 / 2$ ? & OPEI sm & & 1 \\
\hline & $169-158$ & $191 / 1$ & VAL & & 1 \\
\hline & $169-158$ & $192 / 1$ & AT & & 1 \\
\hline & $170 s s-150 s s$ & McCabe к1 & anónimo & Castulo va & $1+3$ \\
\hline & 155 & $200 / 2$ & NAT & & 1 \\
\hline & 153 & $203 / 2$ & C.MAIANI & & 1 \\
\hline & 150 & $206 / 2$ & SAFRA & & 1 \\
\hline & 148 & $215 / 2 a$ & LIво & Castulo vb & $1+1$ \\
\hline & 148 & $216 / 2 a$ & PITIO & & 1 \\
\hline
\end{tabular}

FIg. 6. Moneda romana y local en los ocultamientos surhispanos de la segunda mitad del s. II a. C.

la serie ${ }^{14}$. En este sentido, el ejemplar que comentamos podría encuadrarse en el grupo IV de la ordenación de García-Bellido (1982: 221). Destaca la posición y reducido tamaño del creciente, así

14 La reciente publicación de una interesante reacuñación de una unidad de esta misma serie sobre otra de Lastigi o Carmo no aporta datos concluyentes en cuando a la datación de la emisión castulonense, salvo insistir en su cronología algo más reciente (Martínez Chico, 2014: 10). La buena conservación de la moneda de esta emisión de Castulo documentada en Benagalbón, con respecto al desgaste del as romano con data más reciente $c$. 148 , es un nuevo indicio para apoyar una cronología larga, durante toda la segunda mitad del s. II a. C., al menos. como el perfil y, en general, el contorno de la cabeza del anverso que la distancian de los primeros cuños de la serie. Otro detalle a señalar es el remate de la diadema, con la parcial visión de un nudo del que penden las ínfulas de escaso vuelo. Esta moneda, mejor conservada que los ases romanos más modernos, insiste en retrasar hasta finales del s. II a. C. el cierre de este conjunto monetario de Benagalbón.

Esta es otra singularidad del hallazgo malagueño ${ }^{15}$ pues, tanto en el de Écija como en El Saucejo,

15 Con la prevención, ya indicada anteriormente, sobre la posible inclusión de la moneda n. ${ }^{\circ} 21$ en la Serie III. Su metrología y desgaste o deterioro no lo descartan, pero en todo caso su presencia en este ocultamiento sería 
la moneda castulonense pertenece a la Serie III -símbolo ko- y su datación c. 195-179 es anterior a la de los ases romanos más recientes de ambos conjuntos: $R R C$ 205/2 y $R R C 217 / 2$, c. 151 y 147 a. C., respectivamente. No obstante, estos dos ocultamientos sevillanos contienen, además de moneda -antigua- de Castulo, ejemplares de otras cecas locales: Carmo y de Urso, esta última solo en El Saucejo. La data propuesta para las primeras emisiones de ambos talleres turdetanos, mediados del s. II a. C. (Chaves, 2001: 357; 2002: 16-17), encaja bien con la más precisa que aportan los ases romanos (Chaves y García-Bellido, 1980: 173).

Por último, en este panorama de incertidumbres cronológicas, especialmente en lo que respecta a la data de cierre de este ocultamiento, cabría sacar a colación un importante acontecimiento en la política monetaria romana como fue la reevaluación del denario en 141 a. C. La nueva ratio de 1:16 supuso una devaluación del as de casi un 40\%, primando el poder adquisitivo de la moneda de plata a la vez que dańaba los intereses de las capas sociales más modestas y con un menor acceso al denario (Bransbourg, 2011: 128, 135). Este nuevo panorama monetario debió tener una pronta repercusión en la circulación monetaria hispana, y cabe preguntarse también si pudo afectar a la valoración de estas monedas -los ases acuñados en la primera mitad del s. II a. C. con pesos dispares, pero algunos elevados- en cuanto a su intercambio con el denario, de 1:10 para los ases más pesados y de 1:16 para los ligeros (Bransbourg, 2013: 210-211). Considerando esta posibilidad, así como la data de las monedas romanas más recientes documentadas en el ocultamiento de Benagalbón, los años inmediatamente posteriores al $141 \mathrm{a}$. C. creemos que proporcionan, al menos, un razonable terminus post quem para la formación de nuestro conjunto, y puede que también para los que venimos comentando.

La data de cierre, como hemos visto, plantea muchas dudas pues, si tomamos como principal referente cronológico la cronología y desgaste de los ases romanos, la ausencia de divisores posteriores al minoritaria y, por tanto, bien diferente a la de los otros hallazgos que se comentan.

(C) Universidad de Salamanca
146 a. C., así como de las más tardías y puntuales emisiones de finales de s. II, la data más asumible podría situarse en el tercer cuarto de esta centuria. No obstante, el estado de conservación de la unidad de Castulo con símbolo creciente y la posición que ocupa en esta serie aconseja retrasar algo más su ocultación, en los últimos años del s. II a. C.

\section{El lugar del hallazgo: ¡̨una evidencia engañosa?}

$\mathrm{Si}$, como ya se ha comentado, uno de los aspectos más destacados de este ocultamiento monetario malagueño es su control arqueológico, pues asegura datos normalmente inciertos en otras situaciones como su composición y procedencia, cabe preguntarse ahora por la 'normalidad' de este conjunto monetario, analizado desde el punto de vista de la circulación monetaria de Malaca y su hinterland.

Tomando también como referencia la composición de los dos ocultamientos sevillanos que presentan bastantes similitudes en cuanto a su composición, al incorporar moneda hispana de ámbito regional y local: Castulo y Carmo en ambos casos, además de Urso en El Saucejo (Fig. 5), el de Benagalbón se aparta claramente de este modelo al no incluir ninguna de las amonedaciones de su más cercano ámbito geográfico como es el caso de aquellas de tradición fenicio-púnica, algunas de las cuales estaban emitiendo moneda desde finales del s. III a. C. (Campo y Mora, 1995: 183-187).

Como se ha señalado antes, el yacimiento arqueológico de la Torre de Benagalbón se ubica a escasos $7 \mathrm{~km}$ de la ciudad de Málaga (Rincón de la Victoria, Málaga), en el límite oriental de la bahía del mismo nombre, por lo que en principio podría resultar extraña la ausencia de moneda de Malaka, cuyas copiosas emisiones, en concreto las datadas en el s. II a. C., lógicamente tuvieron un destacado papel en la circulación monetaria de los territorios malacitanos (Campo y Mora, 1995: 174-176). Dos son las explicaciones posibles para justificar tal ausencia. La primera, y quizá más lógica, es el ya comentado criterio de selección -habitual en este tipo 
de hallazgos- que debió aplicar su poseedor y en el que primaba su metrología: ases o unidades de peso y módulo elevados. En este sentido, las ya mencionadas unidades malacitanas, de $c .11 \mathrm{~g}$ de peso y 25 mm de diámetro (Campo y Mora, 1995: 128-130), parece claro que no podían competir con los grandes bronces emitidos desde la primera mitad del s. II a. C. por cecas del Alto y Medio Guadalquivir. Se trata de un perfil metrológico bien diferente del adoptado por las acuñaciones de ciudades costeras de tradición fenicio-púnica (Mora, 2006: 46-48), y que por tanto hacía de estas amonedaciones locales poco o nada atractivas para ser retiradas de circulación en compañía, no se olvide, de los-apreciados-ases romanos.

No obstante, conviene puntualizar que, en lo que conocemos de la circulación monetaria en los territorios malacitanos, no faltan tampoco otras amonedaciones costeras como las de Sexs, Gadir y Carteia, también de pesos y módulos reducidos, además de los siempre apreciados bronces de Castulo y Obulco, documentados tanto en la ciudad de Malaca como en los cercanos enclaves de la desembocadura del río Vélez, Cerro del Mar y Morro de Mezquitilla, pero especialmente también en la comarca de Antequera (Ruiz López, 2012: 62-64).

En cuanto a la proporción de moneda indígena en los tres ocultamientos que vienen centrando nuestros comentarios, cabe destacar la mayor cercanía entre los de Écija y Benagalbón, donde la moneda de Castulo es exclusiva o bien dominante, mientras que en El Saucejo es la de Carmo, con tres ejemplares por solo uno de Castulo, la mejor representada. Este dato podría ser relevante a la hora de considerar el ambiente monetario en el que este último conjunto de monedas fue retirado de circulación. No hay por tanto, en este caso, inconveniente alguno en proponer un entorno cercano al lugar de hallazgo; una observación que no es obvia, pues aunque es una posibilidad habitualmente apuntada para la moneda de oro y plata, cualquier tipo de ocultamiento monetario y, en menor medida también los de bronce, es susceptible de haber sido total o parcialmente formado en puntos alejados del lugar donde, por último, fue ocultado (Campo, 1982: 64).

La dispersión de las monedas de Carmo, así como la emisión a la que pertenecen, apoyan esta posibilidad que tampoco hay que descartar para el ocultamiento de Écija, aunque no resulta tan clara, dada la puntual presencia de la moneda de Carmo con respecto a la de Castulo. No obstante, como apuntan sus editores (Chaves y García-Bellido, 1980: 173), la data de la moneda romana más reciente -151 a. C.- cabría asociarla a los inicios del taller carmonense con una dispersión todavía escasa, por lo que el contenido del ocultamiento de El Saucejo reflejaría mejor la masa monetaria de estos territorios a partir de mediados del s. II a. C. ( $R R C$ 217/2), con un considerable incremento de las cecas del entorno como cómodo complemento del numerario romano y, también, al de Castulo, por lo que parece el mayoritario en ańos anteriores.

En ambos ocultamientos sevillanos, es la Serie III de Castulo la única constatada, mientras que en el yacimiento costero de Benagalbón, con las salvedades indicadas para una de las monedas $-n .^{\circ}$ 21- son las Series IV y v las que conforman el componente indígena de este conjunto monetario. Esta última, como ya se ha dicho, es la que enlaza cronológicamente con los ases romanos más modernos, y también la que muestra un mayor número de hallazgos de la ceca: $18,36 \%$ para la Serie va -símbolo mano- y 11,66\% para la Serie vb -símbolo creciente- (García-Bellido, 1982: 133-135; Ruiz López, 2012: 40).

Volviendo a nuestros comentarios iniciales en este apartado, el ocultamiento de Benagalbón ofrece, dentro de un claro dominio de la moneda oficial romana, una presencia exclusiva de la moneda de Castulo. Aunque no podemos valorar, por falta de hallazgos en estratigrafía, la presencia de moneda de cecas foráneas en la circulación monetaria del entorno de Malaca en la segunda mitad del s. II a. C., nos parece oportuno proponer una explicación alternativa a la formación de este conjunto de monedas procedente del yacimiento arqueológico de Banagalbón: el Alto Guadalquivir. Tanto la buena representación de ases romanos, algunos en un estado de conservación aceptable ${ }^{16}$, como, sobre todo, la

16 En todo caso el número de ejemplares no clasificados por su elevado desgaste es considerablemente menor al de los identificados: cinco sobre veinte. 
concentración de unidades de Castulo de las Series IV y v, sugieren un ambiente monetario de origen donde tanto el numerario romano como, sobre todo, el de Castulo monopolizaba el aporte local de moneda de bronce. Un ambiente, además, renovado con la incorporación de nuevo numerario local y foráneo.

En este punto es obligado referirse a los distritos mineros, y por tanto al castulonense. No solo porque allí se concentra el grueso de los hallazgos de moneda de la ceca (García-Bellido, 1982: 147148; Ruiz López, 2012: 41-42), sino porque se considera uno de los primeros y más importantes focos de atracción de gentes itálicas -comerciantes, soldados...-, cuyo habitual uso de la moneda coincide con la mayor demanda de la misma que genera la intensa explotación de estos territorios (Arévalo, 2000: $48-49)^{17}$. La mayor presencia de la Serie va con símbolo mano, con tres ejemplares sobre uno de la serie paralela con creciente, podría insistir en este contexto minero como probable lugar de formación de este conjunto monetario. En este sentido cabe la posibilidad de que la Serie Iv, sin símbolo y delfín, respectivamente, circularan junto con la Serie v con símbolo mano, por ser ésta la mejor documentada en los cotos mineros, en detrimento de su serie paralela con símbolo creciente (García-Bellido, 1982: 145 y 155).

Tomando en cuenta los matices que ha recibido esta lectura en clave minera de las series paralelas de Castulo (Chaves y Otero, 2002: 184-185), quizá apoyada en nuestro caso por la fuerte presencia de moneda oficial romana, consideramos al distrito castulonense como la mejor opción para situar la formación de este modesto depósito, cuyo dueño pudo transportar luego hasta la costa malagueña. Aunque no se trate de un argumento de peso para justificar esta hipótesis, es oportuno recordar la antigua ruta que comunicaba la capital del distrito minero oretano con Malaca (Sillières, 1990: 401, 412420) (Fig. 6), así como su probable relación con la

17 Aunque por su singularidad y grado de sofisticación, uno de los más interesantes testimonios de este nuevo panorama numismático, de indudable influencia itálica, nos lo proporcionan los conocidos 'plomos monetiformes'; $c f$. Stannard, 2011.

(C) Universidad de Salamanca salida de mineral aprovechando su estratégico puerto (Melchor, 1999a: 255-257; 1999b: 315-316).

En cualquier caso, la importancia de dicha vía en época republicana ha dejado numerosos testimonios arqueológicos (Mateo, 2016: 381-384) y, cómo no, también en su vertiente numismática; tanto en la dispersión de las monedas de Malaca como en la presencia de moneda foránea (Melchor, 1999b: 318-322). No resulta extraño que en los hallazgos de moneda de Castulo en los territorios malacitanos, la comarca de Antequera y otros puntos ubicados en el entorno del Guadalhorce proporcionen los mayores porcentajes (Mora, 2001: 429-431; Melero, 2001: 459-464). Pero entre las cecas mejor representadas también está la de Obulco, al igual que sucede en otros muchos yacimientos del sur peninsular (Arévalo, 1999: 196197; Ruiz López, 2012: 60-63), por lo que resulta llamativo que ninguna de sus copiosas emisiones, contemporáneas de las castulonenses, aparezcan en los conjuntos de bronces de tipo mixto que venimos comentando: Écija, El Saucejo y Benagalbón.

Es posible que esta aparente discriminación no exista $^{18} \mathrm{y}$, en realidad, se deba a la falta de hallazgos de este tipo hasta ahora documentados. Si, como hemos planteado, el ocultamiento de Benagalbón pudo formarse en un punto del distrito castulonense, quizá más oriental y por tanto claramente dominado por la moneda de Castulo (García-Bellido, 1982: 147-148; Mora, 1991: 35), resulta extrańa la ausencia de moneda de Obulco en los ocultamientos de Écija y El Saucejo. Este último permite, además, descartar otra posibilidad como es la sobrevaloración de la moneda de Castulo con respecto a la de Obulco ${ }^{19}$ u otras

18 Pues no faltan en este sentido ejemplos de ocultamientos de moneda de bronce, pero sin moneda romana, datados entre la segunda mitad del s. II a. C. y los primeros años de la centuria siguiente. Además de los señalados en su momento por Chaves, 1991-1993: 269; 1994 y Ruiz López, 2010, destaca el más reciente de Arjonilla (Jaén), compuesto por 11 unidades de Obulco de las Series IV y v, en el que sobresale tanto su número y selección de nominales como también su localización, la Campiña Occidental, lejos de los cotos mineros. Cf. Fornell y Ruiz López, 2013.

19 Fuera, se entiende, de su ámbito local de circulación y sin que ello suponga olvidar el mayor volumen de emisión y circulación de la moneda castulonense, o sus abundantes imitaciones. 


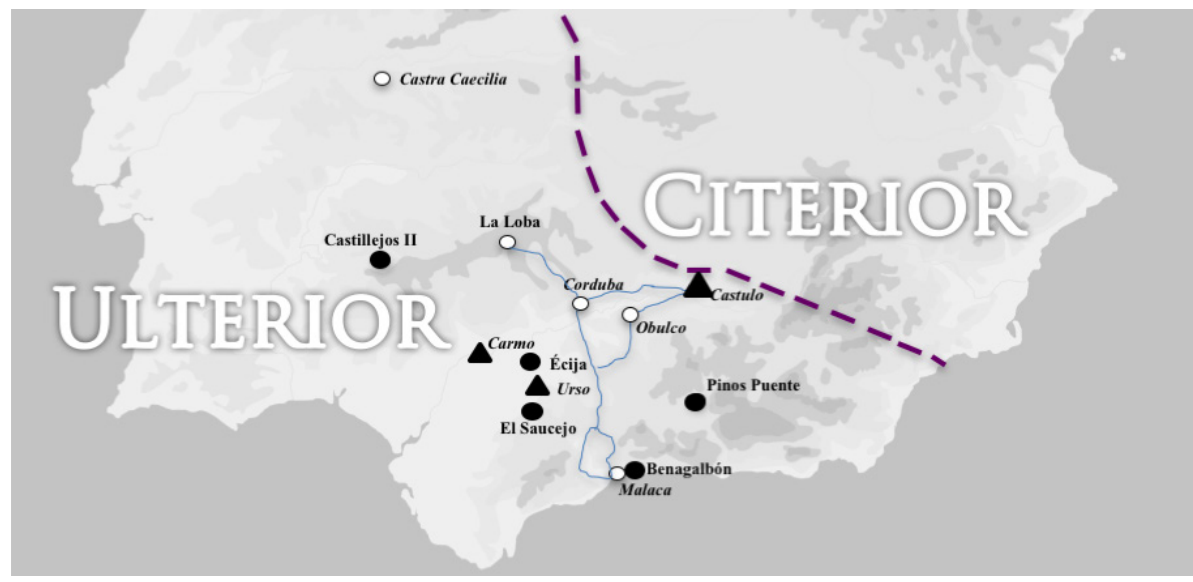

Fig. 7. Localización del ocultamiento de Benagalbón, con la indicación de los otros hallazgos, cecas y topónimos citados en el texto. También se indica el trazado de la vía CastuloMalaca, con sus posibles itinerarios alternativos, según Sillières (1990) y Melchor (1993a).

emisiones locales, pues tanto las de Carmo como las menos abundantes de Urso capitalizan el numerario indígena en este conjunto monetario.

Los hallazgos aislados, procedan o no de excavación, demuestran que la moneda de Obulco tuvo una buena aceptación y circuló de manera conjunta con la de Castulo. Ello se deduce, entre otros casos, de los hallazgos monetarios en un importante coto minero como La Loba (Fuente Obejuna, Córdoba), donde además de una nutrida presencia de moneda de la $\mathrm{Ci}$ terior-Arekorata, Sekaiza, Bolskan, Titiakos, etc.- las cecas de la Ulterior destacan con Castulo y Obulco a la cabeza (Chaves y Otero, 2002: 163-172) ${ }^{20}$. A pesar de su cronología más tardía, también resulta de gran interés el análisis de la circulación monetaria en el campamento romano de Cáceres el Viejo pues, además de contar con una buena presencia de numerario de Obulco -12 ejemplares-, pero muy por debajo de Castulo -59 ejemplares-, nos ofrece una imagen de cambio en la circulación monetaria de la Ulterior-Baetica entre finales del s. II y los primeros años

20 Como suele ser habitual, de las 76 monedas hispanas documentadas, Castulo con 29 monedas es la ceca mejor representada, mientras que Obulco cuenta con 18 ejemplares. Las proporciones son igualmente significativas, en el caso de Castulo con la va -mano- a la cabeza. Cabe señalar que, si bien aparecen divisores, su proporción es muy escasa respecto a las unidades o valores altos. de la centuria siguiente, como entre otros detalles se deduce de la mayor presencia de divisores (Abásolo et al., 2008: 134-136; Ripollès, 2014: 58).

De la composición de los ocultamientos monetarios que venimos comentando en la masa monetaria circulante a partir del 146 a. C., se puede deducir que la moneda de bronce romana comparte cada vez mayor protagonismo con las emisiones locales, cuyo número y volumen de emisión experimentan ahora un notable incremento. Sin duda conectado con las necesidades y limitaciones locales, pero igualmente explicable también desde una perspectiva más amplia, en el marco de la política monetaria romana en Hispana (Ripollès, 2014: 64). No obstante, estos hallazgos, sobre todo en el sur peninsular, se muestran todavía alejados de la mayoritaria presencia de moneda local $\mathrm{y}$, sobre todo, de la inclusión de divisores o moneda de menor peso y módulo que será frecuente encontrar más tarde, tanto en hallazgos de excavación ${ }^{21}$ como también en ocultamientos más tardíos (Chaves, 1991-1993: 272-273). Esta evidencia es, quizá también, otro argumento indirecto a favor de no retrasar mucho el momento de ocultación de Benagalbón, pues, según el perfil de los documentados en la Ulterior a principios del s. I a. C., los divisores de Castulo e incluso moneda de Malaka podrían haber sido incluidos en este pequeño escondrijo.

21 Entre otros ejemplos, es significativo comparar el tipo de moneda recuperado en los campamentos numantinos con el de Cáceres el Viejo. Si en el primero la presencia de moneda hispana es modesta, y en consecuencia también la de divisores (Jiménez, 2014: 385-386), en el campamento lusitano su proporción es mucho más abultada, aunque se mantiene una alta proporción de ases romanos en su mayor parte ilegibles por su prolongada circulación (Blázquez, 2002: 60-68; Abásolo et al., 2008: 130 y 136; Ripollès, 2014: 58). 


\section{Ases romanos y unidades indígenas: ¿prestigio o valor de mercado?}

La composición de los ocultamientos hispanos con moneda de bronce oficial romana que comentamos se presta también a otros comentarios como la valoración que pudo tener la moneda romana en ámbito indígena o, al contrario, el bronce local en manos de romanos o itálicos. Naturalmente seguimos hablando de moneda de bronce, pues Roma no permitió ninguna emisión de moneda de plata en la Ulterior-Baetica, por lo que, pocos años después del final de la Segunda Guerra Púnica, denarios romanos y 'denarios ibéricos' conformaban el numerario de mayor poder adquisitivo entre la población indígena y los emigrantes itálicos. Los numerosos tesorillos de moneda de plata localizados en el mediodía hispano, algunos de composición mixta (Gozalbes y Torregrosa, 2014: 286), y, sobre todo, los hallazgos de excavación en los que se documentan circulando conjuntamente denarios romanos y bronces romanos e indígenas, como vemos en los campamentos romanos, así como en poblados mineros como $\mathrm{La}$ Loba (Chaves y Otero, 2002: 209-210), permiten suponer que la moneda de bronce hispana estuvo totalmente integrada en el sistema romano; entendiendo como tal el que impuso la administración romana a los territorios recién incorporados.

Pero, contrariamente a las acuñaciones de plata ibéricas, cuya paulatina adecuación a la metrología del denario es de lo más significativa, el panorama del bronce es bien diferente, primando los pesos locales que a su vez parecen responder a diferentes tradiciones metrológicas, sin descartar tampoco la romana, a la que en todo caso se aproximan (García-Bellido, 2000-2001: 564-566; Mora, 2006: 44). Recientes valoraciones sobre este complejo panorama han incidido en la necesidad de buscar nuevos enfoques atendiendo al evidente problema que supone ofrecer un marco explicativo común al carácter tan heterogéneo que presentan las monedas hispanas de bronce, especialmente en la Ulterior (Gozalbes, 2010: 52 y 54).

Con independencia del grado de ajuste de los pesos locales con respecto a la libra romana -una práctica habitual entre los usuarios de la moneda antigua-, cabe suponer que debió existir una concordancia entre la moneda de bronce indígena y la de plata impuesta por Roma; al menos en términos contables. Tampoco conocemos si los bronces romanos e indígenas tuvieron una valoración paritaria, lógicamente atendiendo a sus características metrológicas y puede incluso que metalográficas ${ }^{22}$. Y ello con independencia de su ya comentada circulación conjunta en sitios singulares como los campamentos republicanos antes mencionados, que confirma su integración en el sistema monetario hispano tutelado por Roma, pero no ofrece información sobre el aprecio de la moneda romana con respecto a la indígena, equivalente en peso y, en parte también, en módulo.

¿Era su valor paritario? Y en caso afirmativo ¿se aplicaba la misma ratio de intercambio para acceder a la moneda de plata?, ¿qué posición adoptamos ante el componente fiduciario y el valor intrínseco de la moneda de bronce romana y, por ende, de la local hispana?23, y, por último, ¿cómo pudo afectar a esta valoración la ratio plata-bronce en Hispania, por otro lado, puede que condicionada por su abundancia y calidad? Las respuestas a tales preguntas son complejas y algunas enlazan, a su vez, con otras consideraciones de calado, como la distinción entre las diferentes esferas de uso de la moneda antigua, y en concreto de la de bronce hispana de época republicana (Chaves, 2007: 220221). Podemos asumir una valoración laxa para el numerario de bronce circulante en ámbito privado, en el que usuarios le pudieron otorgar un valor de cambio consensuado atendiendo, probablemente, a su aspecto y metrología (Gozalbes, 2012: 48). Pero el problema, desde nuestro punto de vista, es cómo se produjo su encaje, por modesto que fuera su

22 Aunque algunas amonedaciones de bronce de la Citerior, como la de Emporion con leyenda Untikesken, parecen confirmarlo. Cf. Campo, 2000: 64. Gozalbes (2012: 64) recuerda la importancia de considerar el módulo de las monedas como valiosa referencia a la hora de distinguir posibles nominales o establecer relaciones de intercambio entre emisiones de diferente procedencia y patrones de origen.

23 Asumiendo como propone Gozalbes (2012: 62) un equilibrio entre ambos componentes que no desentona con la reciente propuesta para la moneda romana desarrollada por Bransbourg (2011: 102-116). 
valor de mercado, en la esfera oficial romana; esto es, en pagos o servicios dependientes o estrechamente relacionados con la administración.

En este punto, tanto el ocultamiento de Benagalbón como otros que venimos comentando, datados en la segunda mitad del s. II a. C., pueden proporcionar alguna información. Así, de su composición se deduce un mayor aprecio por la moneda romana, capitalizada por el as, el único tipo de moneda y nominal recogidos en el ocultamiento de Pinos Puente y en el de Castillejos II, ya citados. Pero también en los ocultamientos mixtos, con la excepción de El Saucejo, el as romano supera a la moneda indígena; naturalmente unidades de peso y módulo cercanos a la moneda romana. El de Benagalbón es el que ofrece una desproporción más clara en este sentido y el que, en nuestra opinión, permite apuntar al menos que, en la circulación monetaria de la Ulterior entre los años centrales y segunda mitad del s. II a. C., el bronce romano pudo gozar de un mayor prestigio, desde luego entre la población itálica, pero posiblemente también entre la indígena, quizá por su condición de moneda supralocal y puede que por ello mejor valorada -o aceptada- en el mercado.

$\mathrm{Al}$ menos, igual que sucede en nuestro caso, los modestos ahorradores que retiraron estos bronces de la circulación conocían el valor de intercambio del as romano con respecto al denario. $\mathrm{O}$ al menos eso creían hasta poco después del 141 a. C., cuando la revaluación de la moneda de plata romana trastocó todo el sistema a favor del denario (Bransbroug, 2011: 128), pero indirectamente también de la moneda de bronce local, cuyo sobrecoste de producción y transporte se transfiere del erario público a los provinciales.

\section{Epílogo}

Además de incrementar el escaso número de ocultamientos monetarios de este tipo documentados en suelo hispano, y especialmente en la Ulterior-Baetica, el de Benagalbón es el único de composición mixta que ha sido recuperado en una excavación. Su ocultación se propone en los ańos finales del s. II a. C., en todo caso después del 146 y 141 a. C. y, posiblemente, no mucho más tarde de la recuperación de la emisión de divisores o de la fugaz reaparición del $\mathrm{as}^{24}$, como muestra el ocultamiento de Torelló. A pesar de su lugar de hallazgo, se plantea la posibilidad de que este conjunto de monedas se formase en el Alto Guadalquivir, desde donde pudo ser trasladado por su dueño hasta la costa malacitana, aprovechando la antigua y transitada ruta Castulo-Malaca. Esta importante vía de comunicación, además de concentrar un intenso tráfico de mercancías, favoreció el desplazamiento de gentes entre la costa mediterránea y el interior bético. La posibilidad de que en el yacimiento de Benagalbón existiera, previamente a la instalación de una gran villa-factoria a inicios de la época imperial, una actividad metalúrgica bien pudo favorecer la llegada de personal especializado, mineros o metalúrgicos de la región castulonense, posibilitando así el acarreo de moneda propia o foránea desde su lugar de origen. Así, la composición del ocultamiento monetario que aquí estudiamos quedaría, en nuestra opinión, mejor explicada ${ }^{25}$.

Al menos en los ocultamientos conocidos de la Ulterior-Baetica, datables en la segunda mitad del s. II a. C., el aprecio del bronce indígena se centra en las monedas de pesos y módulos cercanos al as romano, pero el ocultamiento de Benagalbón incluye como novedad un semis de cronología equiparable al grupo más reciente de los ases de mediados del s. II a. C. Esto parece indicar que, al igual que en Torelló, las posibles excepciones en cuanto al acopio de grandes bronces se centraron más en la moneda romana. Esta y otras observaciones hacen pensar que la moneda oficial romana gozó de un mayor prestigio que la indígena, y que ésta posiblemente no pudo llenar el vacío creado

24 Con un puntual repunte hacia los antiguos pesos unciales (Crawford, 1985: 183 y 185) que, de ser coetáneo a la formación de nuestro depósito, quizá podrían haber incentivado su retirada de circulación. Pero la rareza de estas emisiones es un serio inconveniente para sopesar este argumento ex silentio.

25 Insistiendo, además, en una de las posibles causas de la dispersión de ciertas amonedaciones, como "indicio de desplazamiento de gentes" propuesto para Castulo por García-Bellido (1982: 137-140). 
por la brusca interrupción del aprovisionamiento de bronce romano, justificando así en buena medida la aparición de imitaciones de ases y semis (Ripollès, 2014: 69-70; Ripollès y Gozalbes, 2016: 302 26, pero también un mayor aprecio de los viejos ases.

\section{Bibliografía}

Abásolo, J. A.; González, M. L. y Mora, B. (2008): "Recientes investigaciones en el campamento de Cáceres el Viejo". En Sanabria, P. J. (ed.): Arqueología urbana en Cáceres. Cáceres: Museo de Cáceres, pp. 115-143.

Arévalo, A. (1999): La ciudad de Obulco: sus emisiones monetales. Sigüenza: Edic. Librería Rayuela.

Arévalo, A. (2000): "La moneda hispánica en relación con la explotación minera y agrícola”. En CAMPO, M. (ed.): Moneda $i$ administració del territori. Barcelona: GNC, pp. 37-56.

Arévalo, A. y Marcos, C. (1998): El depósito monetal de Torelló d'en Cintes (Mahón, Menorca). Barcelona: ANE.

Blázquez, C. (1988): "Tesorillos de moneda republicana en la península Ibérica. Addenda a Roman Republican Coin Hoards", Acta Numismàtica, 17-18, pp. 105-142.

Blázquez, C. (2002): Circulación monetaria en el área occidental de la Peninsula Ibérica. La moneda en torno al 'Camino de la Plata'. Archéologie et Histoire Romaine, 6. Montagnac.

Bransbourg, G. (2011): "Fides et Pecunia Numerata Chartalism and Metallism in the Roman World Part 1: The Republic", American Journal of Numismatic, 23, pp. 87-152.

Bransbourg, G. (2013): "Fides et Pecunia Numerata Part II: The Currencies of the Roman Republic", American Journal of Numismatic, 25, pp. 179-242.

Campo, M. (1982): "Circulación monetaria y tesoros hispánicos de época preimperial”, Numisma, 1174176, pp. 51-70.

Campo, M. (2000): "Moneda, organització i administració del nordest de la Hispania Citerior (del 218 a l'inici del segle i a. C.)". En Campo, M. (ed.):

26 Que, sin embargo, no aparecen en los ocultamientos que venimos comentando -en realidad en ninguno de los conocidos-, indicando quizá ambientes de circulación todavía separados, especialmente en lo que respecta a los ases.
Moneda i administració del territori. IV Curs d'Història monetària de Hispania. Barcelona: GNC, pp. 57-75.

Campo, M. y Mora, B. (1995): Las monedas de Malaca. Madrid: FNMT.

Chaves, F. (1991-1993): "Consideraciones sobre los tesorillos de moneda de bronce en Hispania. República e inicios del Imperio Romano. II", Acta Numismática, 21-23, pp. 267-284.

Chaves, F. (1994): "Tesaurizaciones de monedas de bronce en la península Ibérica. La República y el inicio del Imperio: nuevos datos. I". En SAÉz, P. y Ordóñez, S. (eds.): Homenaje al profesor Presedo. Sevilla: Univ. de Sevilla, pp. 375-389.

Chaves, F. (2001): "La ceca de Carmo". En Caballos, A. (ed. lit.): Carmona Romana. II Congreso de Historia de Carmona (Carmona, 1999). Carmona: Univ. de Sevilla, pp. 339-362.

Chaves, F. (2002): “Urso: la historia pendiente". En Chaves, F. (coord.): Urso: a la búsqueda de su pasado. Osuna: Ayto. de Osuna, pp. 5-26.

Chaves, F. (2005): Monedas Romanas. I. República. Publicaciones del Catálogo del Gabinete de Antigüedades de la Real Academia de la Historia. Madrid: RAH.

Chaves, F. (2007): "Origen, uso y función de la moneda en la sociedad hispana: ss. IV-I a. C.”. En Moucharte, G.; Borba Florenzano, M. B.; Callatä̈, F.; Marchetti, P.; Smolderen, L. y Yannopoulos, P. (eds.): Liber Amicorum T. Hackens. Louvain-la-Neuve, pp. 213-222.

Chaves, F. y García-Bellido, M. P. (1980): “Tesorillo de bronces del s. II a. C. hallado en el término de Écija”. En II Simposio Numismático de Barcelona. Barcelona: sCEN, pp. 171-174.

Chaves, F. y Otero, P. (2002): "Los hallazgos monetales”. En Blázquez, J. M.; Domergue, C. y SiLlières, P. (dirs.): La Loba (Fuenteobejuna, province de Cordoue, Espagne): la mine et le village minier anticúes. Bordeaux: Inst. Ausonius, pp. 163-230.

Chaves, F. y Pliego, R. (2007): "Instrumentos de medida de pesos en la Hispania antigua", Sautuola, XIII, pp. 237-250.

Conejo, N. (2014): "El conjunto de ases romano-republicanos del yacimiento prerromano de Castillejos II, Fuente de Cantos (Badajoz)", Revista de Estudios Extremeños, LXX (1), pp. 11-34.

Crawford, M. H. (1969): Roman Republican coin hoards. London: RNS.

Crawford, M. H. (1974): Roman Republican Coinage. Cambridge: cup. 
Crawford, M. H. (1985): Coinage and money under the Roman Republic: Italy and the Mediterraean economy. Berkeley: UCP.

Fornell, A. y Ruiz López, I. D. (2013): “Un conjunto de monedas de Obulco en Arjonilla (Jaén)", Numisma, 257, pp. 47-67.

García-Bellido, M. P. (1982): Las monedas de Cástulo con escritura indígena. Historia numismática de una ciudad minera. Barcelona: ANE.

García-Bellido, M. P. (2000-2001): "Roma y los sistemas monetarios provinciales. Monedas romanas acuñadas en Hispania en la Segunda Guerra Púnica”, Zephyrus, LIII-LIV, pp. 551-577.

García-Bellido, M. P. y Blázquez, C. (2001): Diccionario de cecas y pueblos hispánicos. Vol. I. Introducción a la numismática antigua de la península Ibérica. Vol. II. Catálogo de cecas y pueblos que acuñan moneda. Madrid: CSIC.

Gozalbes, M. (2012): "Peso y valor de las monedas de bronce en la Hispania republicana. El complejo panorama de una época convulsa”. En CAMPO, M. (ed.): La moneda en temps de Crisis. XVI Curs d'Història Monetària d'Hispània. Barcelona: GNC, pp. 47-68.

Gozalbes, M. y Torregrosa, J. M. (2014): “De Iberia a Hispania. Plata, dracmas y denarios entre los ss. vI y I a. C.", Archivo de Prehistoria Levantina, 30, pp. 275-316.

JiméneZ, A. (2014): "Ejército y moneda en Numancia. El campamento in de Renieblas". En Cadiou, F. y Navarro, M. (eds.): La guerre et ses traces. Conflits et sociétés en Hispanie à l'époque de la conquête romaine (IIIe-Ier s. a. C.). Mémoires, 37. Bordeaux: Édit. Ausonius, pp. 369-393.

Martínez Chico, D. (2014): “As de Castulo sobre un probable as con leyenda latina, ¿una nueva reacuñación interbilingüe de la Ulterior?", Nummus, 2. a s., XXXVII, pp. 7-11.

Mateo, D. (2016): “Tráfico portuario y comercio anfórico entre Malaca y la cuenca minera cordobesa en el periodo tardorrepublicano". En JÁrregA, R. y Millet, P. B. (eds.): Amphorae ex Hispania: paisajes de producción y consumo. Monografías Ex officina hispana, III. Tarragona: Ex Officina Hispana-ICAC, pp. 376-388.

McCabe, A. (2013): “The Anonymous Struck Bronze Coinage of the Roman Republic: A Provisional Arrangement”. En Van Alfen, P. G. y Witschonke, R. B. (eds.): Essays in Honor of Roberto Russo. Zürich-London: Numismatica Ars Classica, pp. 101-273.
Melchor, E. (1999a): "La red viaria romana y la comercialización de los metales de Sierra Morena". En Centeno, R. M. S.; García-Bellido, M. P. y Mora, G. (coords.): Rutas, ciudades y moneda en Hispania (II EPNA). Anejos de AEspa, Xx. Madrid: pp. 311-322.

Melchor, E. (1999b): "Contactos comerciales en el Alto Guadalquivir, el valle medio del Betis y la zona costera malagueña durante el alto imperio”, Habis, 30, pp. 253-269.

Melero, F. (2001): "Circulación monetaria en el Valle de Abdalajís: las cecas hispánicas”. En WülfF, F.; Cruz, C. y Martínez Maza, C. (eds.): II Congreso de Historia Antigua de Málaga: comercio y comerciantes en la Historia Antigua de Málaga (s. VIII a. C.- 711 d. C.). Málaga: Diput. de Málaga, pp. 457-467.

Mora, B. (1991): "Un conjunto de monedas hispanas halladas en Cazorla”, Gaceta Numismática, 102, pp. 33-42.

Mora, B. (2001): "La circulación monetaria en los territorios malacitanos durante la antigüedad”. En Wulff, F.; Cruz, C. y Martínez Maza, C. (eds.): II Congreso de Historia Antigua de Málaga: comercio y comerciantes en la Historia Antigua de Málaga (s. VIII a. C.- 711 d. C.). Málaga: Diput. de Málaga, pp. 419-455.

MorA, B. (2006): "Metrología y sistemas monetarios en la Península Ibérica (ss. V-I a. C.)". En Actas XII Congreso Nacional de Numismática. Madrid: FNMT, pp. 23-61.

Recio, A. y Perdiguero, M. (1986): "La Loma: Un yacimiento fenicio en la provincia de Málaga”, Mainake, 4-5, pp. 111-132.

Ripollès, P. P. (1982): La circulación monetaria en la Tarraconense Mediterránea. Valencia: Diput. Prov. de Valencia.

Ripollès, P. P. (2014): "La política monetaria de los romanos durante la época republicana en la península Ibérica y las emisiones locales”, AIIN, 60, pp. 19-83.

Ripollès, P. P. y Gozalbes, M. (2016): "Imitaciones hispanas de ases romanos republicanos", Archivo de Prehistoria Levantina, xxxI, pp. 283-304.

Rodríguez Oliva, P. y Beltrán Fortes, J. (2008): "Arqueología de las villae romanas de la costa malacitana”, Habis, 39, pp. 223-243.

Rodríguez Vinceiro; Fernández Rodríguez, L. E.; Suárez Padilla, J. y Romero, J. C. (1996): "Aproximación a la explotación de los recursos abióticos durante la Protohistoria en la provincia 
de Málaga”. En Wülff, F. y Cruz, G. (eds.): Historia Antigua de Málaga y su provincia. Málaga: Arguval, pp. 189-203.

Ruiz López, I. D. (2010): La circulación monetaria en el sur peninsular durante el periodo romano-republicano. Granada: Univ. de Granada.

Ruiz López, I. D. (2012): Las cecas ibéricas meridionales de la Hispania Ulterior y su circulación monetaria. Acuñaciones y dispersión monetal de las ciudades ibéricas del sur peninsular. BAR Int. Ser., S2333. Oxford: Archaeopress.

Serrano, E. (1985): "Arqueología romana malagueña: Torre de Benagalbón”, Baetica, 6, pp. 191-199.

Sillières, P. (1990): Les voies de communication de l'Hispanie méridionale. Bordeaux: Publications du Centre Pierre Paris.
Stannard, C. (2011): "The iconography of two groups of struck lead from Central Italy and Baetica in the second and first centuries BC". En Holmes, N. (ed.): Proceedings XIVth International Numismatic Congress (Glasgow, 2009). Glasgow, pp. 1046-1055.

Villaronga, L. (1980): "Tesorillo de bronces de El Saucejo: Sevilla", Quaderni Ticinesi, 9, pp. 175-179.

Villaronga, L. (1993): Tresors monetaris de la Peninsula Ibèrica anteriors a August: repertori i anàlisi. Barcelona: IEC.

Villaronga, L. (1994): Corpus Nummum Hispaniae ante Augusti Aetatem. Madrid: José Herrero sA.

Villaronga, L. y Benages, J. (2011): Ancient Coinages of the Iberian Peninsula. Barcelona: IEC. 
